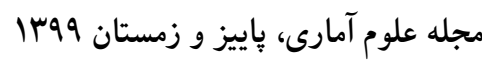

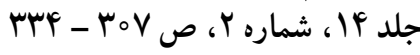

DOI: $10.29252 /$ jss.14.2.307

تحليل بيزى دادههاى شمارشى فضايى در جوامع متناهى با رهيافت معادلات ديفرانسيل جزئى تصادفى

$$
\text { نغار اقبال، حسين باغيشنى }
$$

كروه آمار، دانشكده علوم رياضى، دانشكاه صنعتى شاهرود

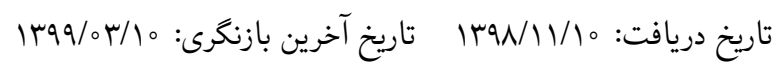

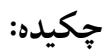

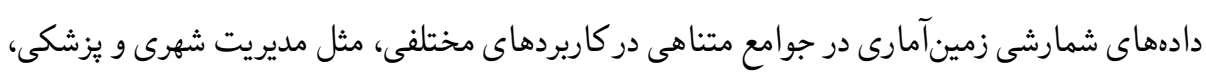

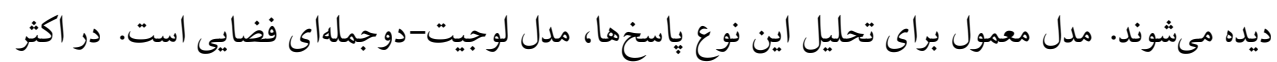

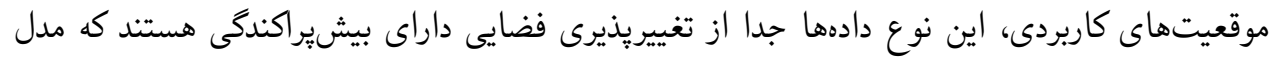

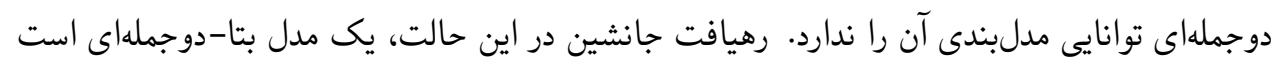

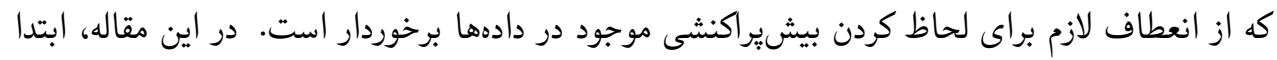

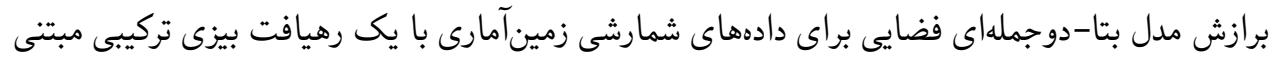

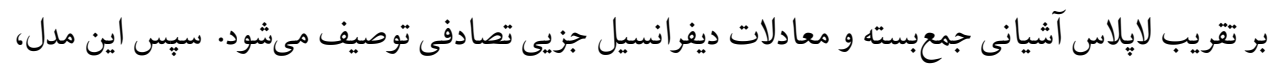

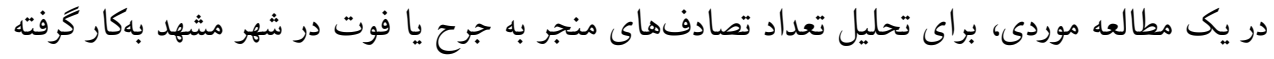

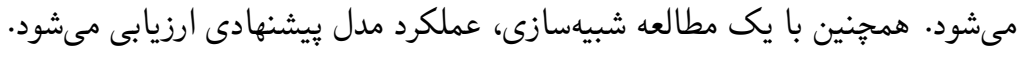
وازدهاى كليدى: بتا-دوجملهاى فضايى، بيشيراكنش، رهيافت بيزى تقريبى، معادلات ديفرانسيل جزيى

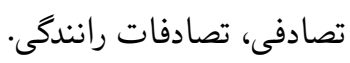




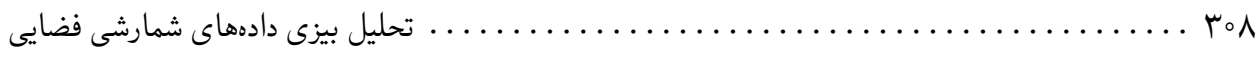

\section{|}

تعداد رخدادهاى يك بديده (تعداد موفقيتها) در يك جامعه متناهى، با همراه بودن اطلاعات مكانى رخداد

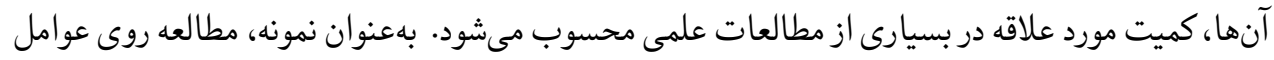

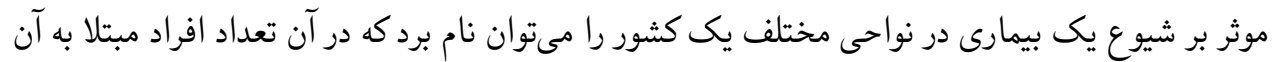

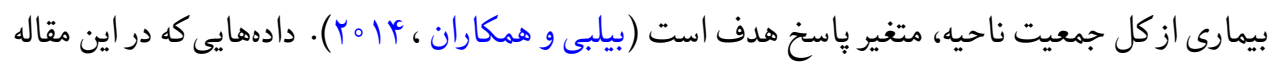

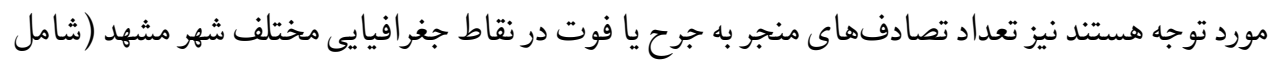

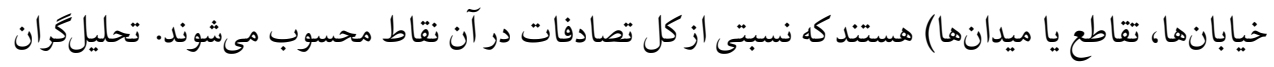

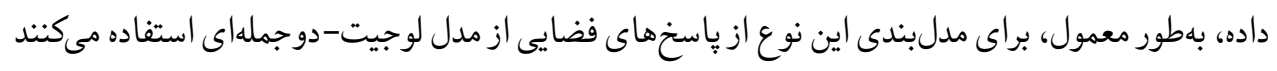

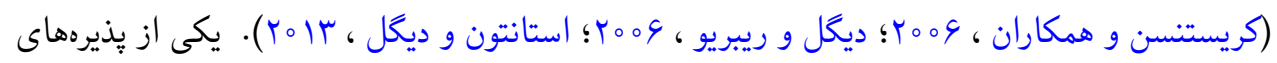

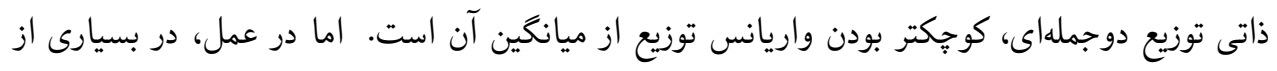

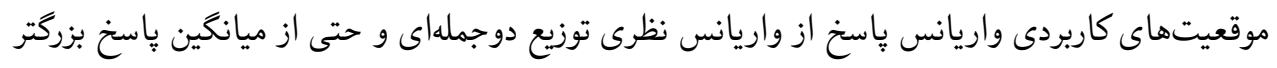

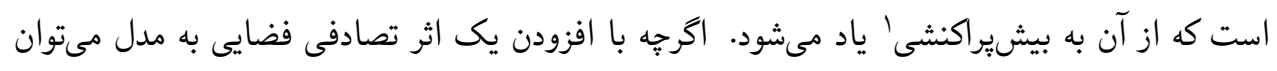

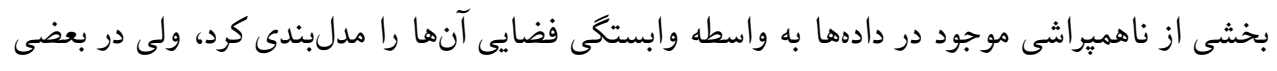

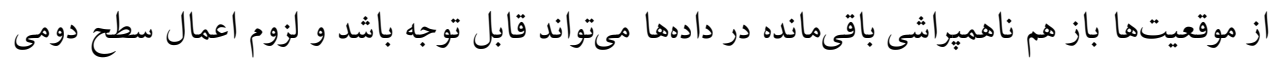

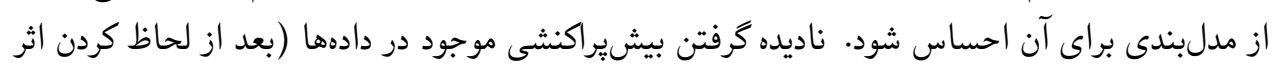

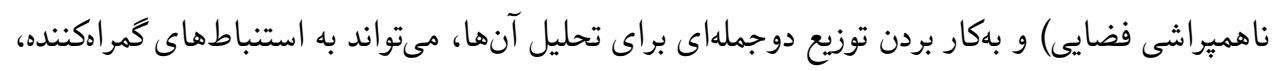

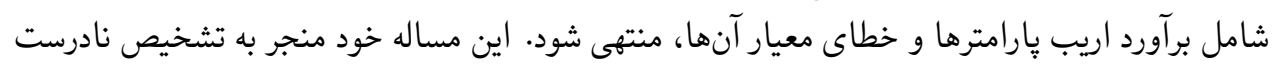

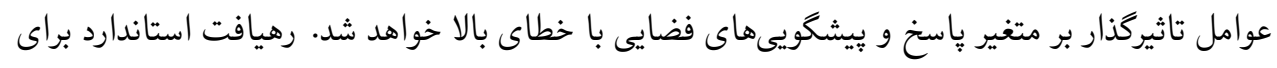

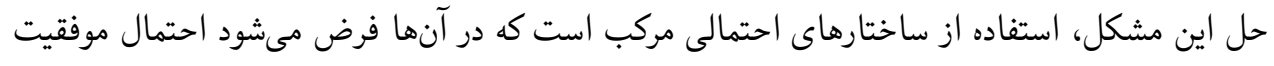

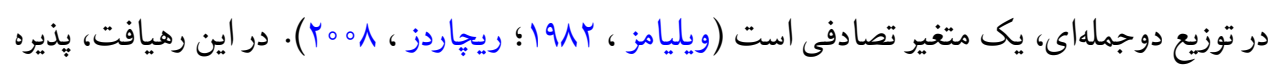

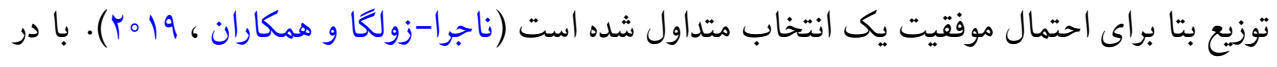

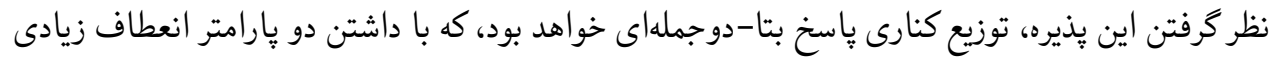

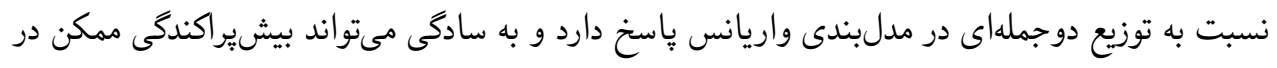
دادهها را مدلبندى كند.

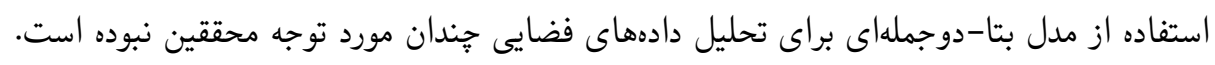

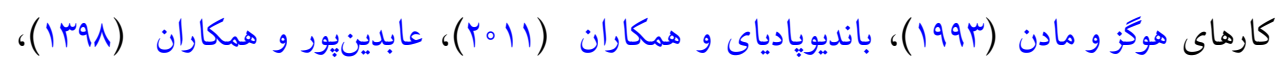




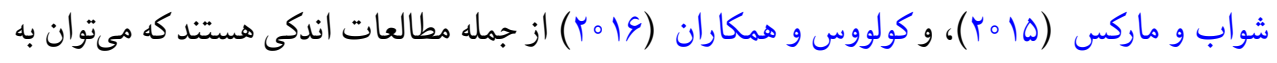

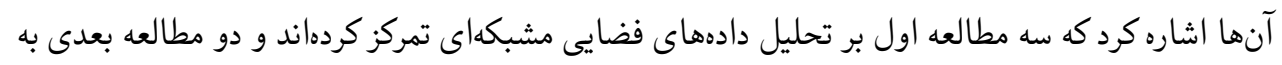

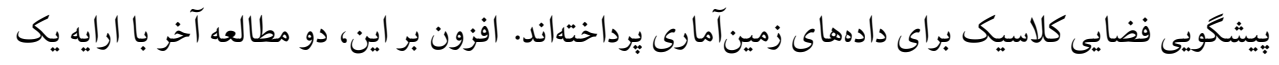

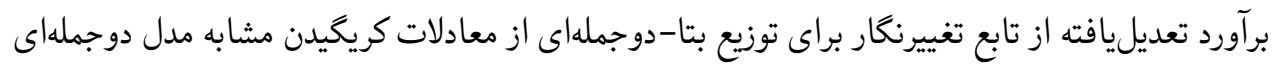

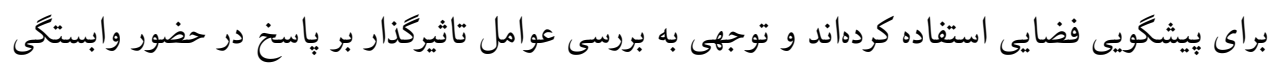

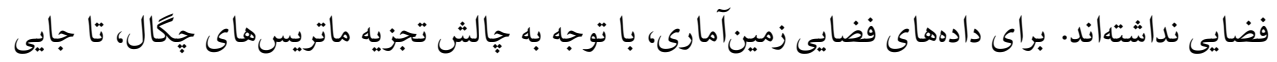

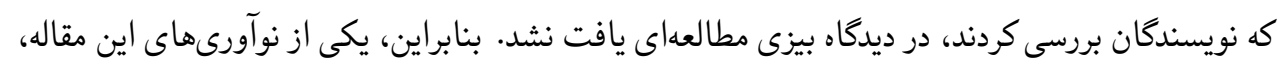

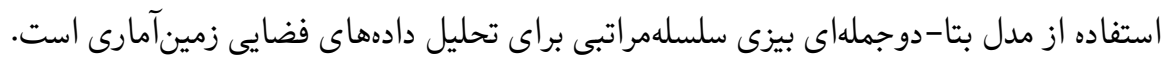

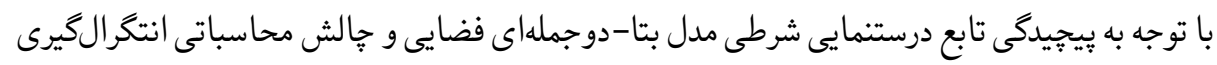

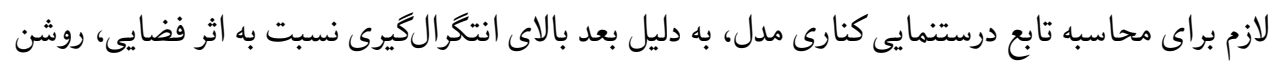

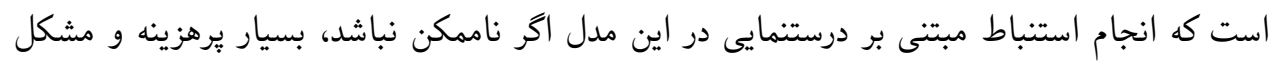

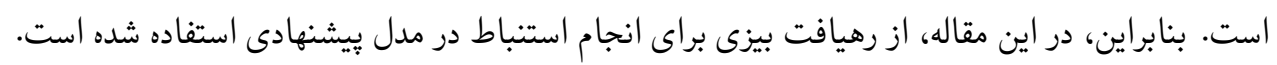

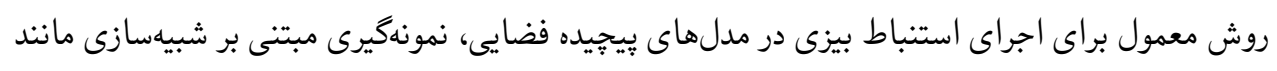

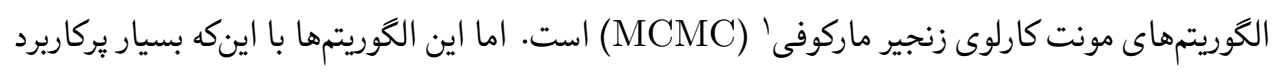

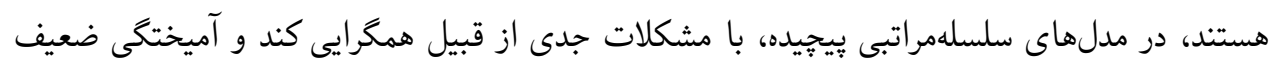

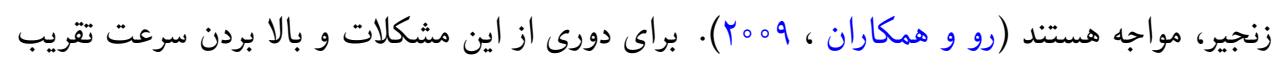

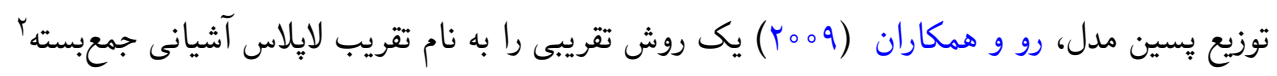
(INLA)

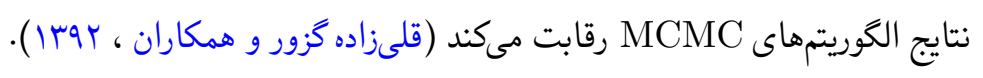

سرعت بالاى روش INLA در برازش مدلهاى فضايى، به دليل گسسته بودن ناحيه تحت مطالعه

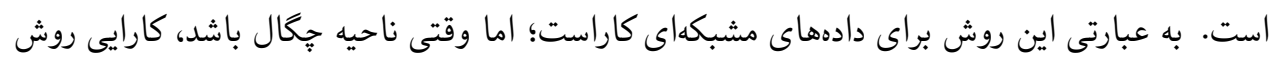

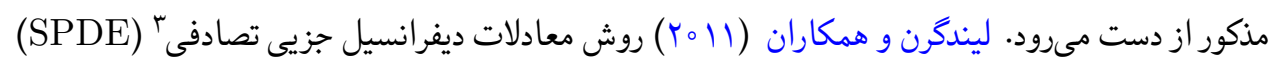

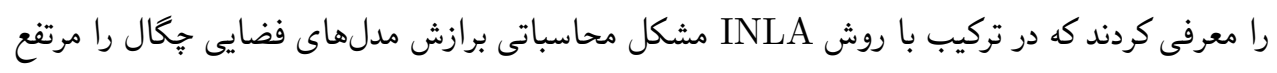

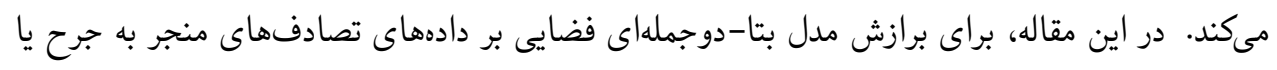

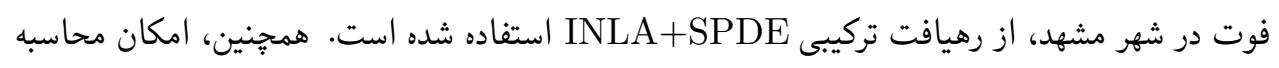

\footnotetext{
${ }^{1}$ Markov Chain Monte Carlo

${ }^{2}$ Integrated Nested Laplace Approximation

${ }^{3}$ Stochastic Partial Differential Equations
} 
تحليل بيزى دادهاى شمارشى فضايى

r.

معيارهاى مختلف ارزيابى برازش مدل با روش INLA كمك كرده است تا بتوان جنبههاى مختلف برازش،

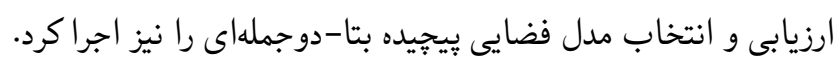

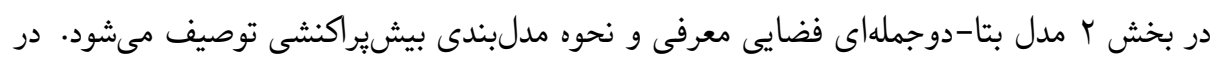

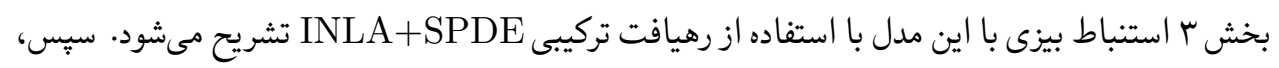

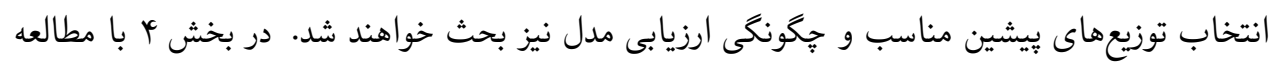

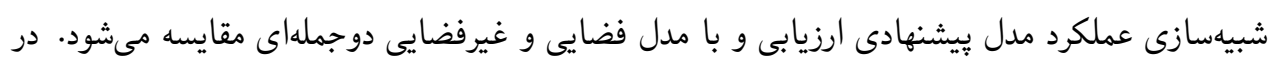
بخش ه دادههاى تعداد تصادفهاى منجر به جرح يا فوت در شهر مشهد تحليل و نتايج آن تفسير ميى مشوند.

\section{r}

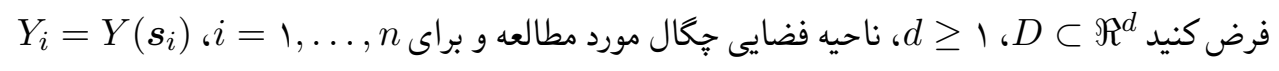

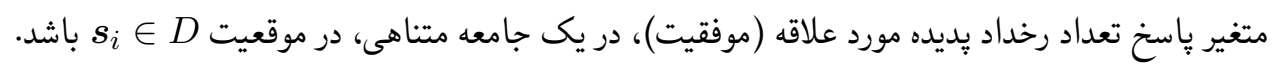

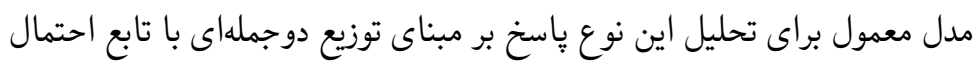

$$
\mathrm{P}\left(Y_{i}=y_{i}\right)=\left(\begin{array}{c}
n_{i} \\
y_{i}
\end{array}\right) \pi_{i}^{y_{i}}\left(1-\pi_{i}\right)^{n_{i}-y_{i}}, \quad y_{i}=\circ, 1, \cdots, n_{i}
$$

ساخته مىشود، كه در آن مشاهده باسخ در موقعيت $y_{i}=y\left(\boldsymbol{s}_{i}\right)$

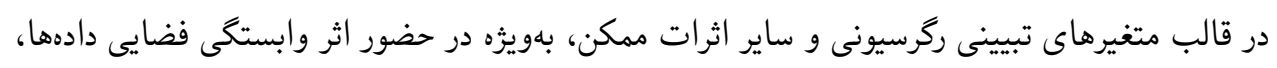

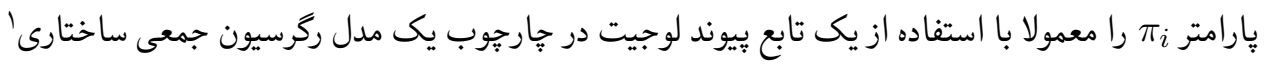

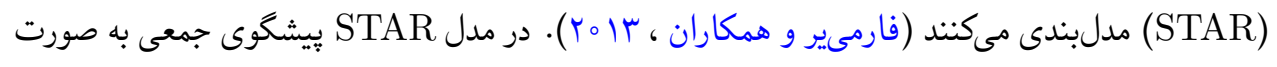

$$
\ln \left(\frac{\pi_{i}}{1-\pi_{i}}\right)=\eta_{i}=\alpha+\sum_{j=1}^{n_{f}} f^{(j)}\left(u_{j i}\right)+\sum_{k=1}^{n_{\beta}} \beta_{k} z_{k i}+\epsilon_{i}, \quad i=1, \cdots, n_{d}
$$

نوشته مىشود، كه در آن \}(·)

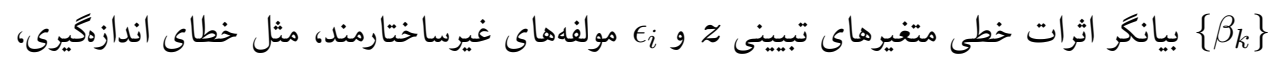


هستند. با توجه به صورتهاى متنوعى كه توابع $\}$ STAR

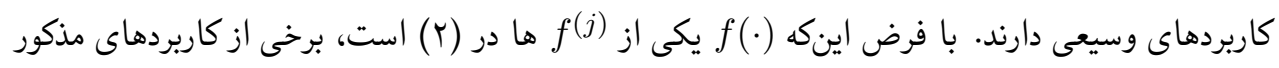
عبارتند از الف- اثرات غيرخطى (نايارامترى) متغيرهاى تبيينى: براى در نظر كرفتن اثر هموار (نايارامترى) يك رئ

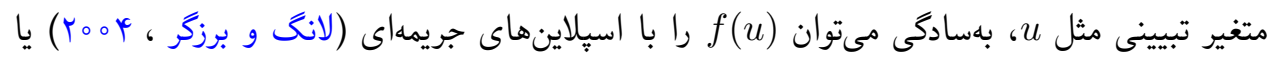

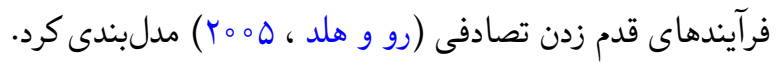

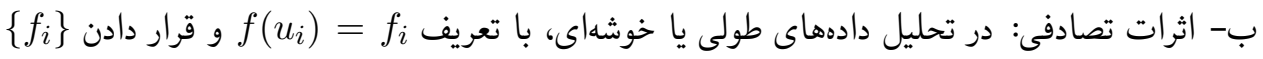

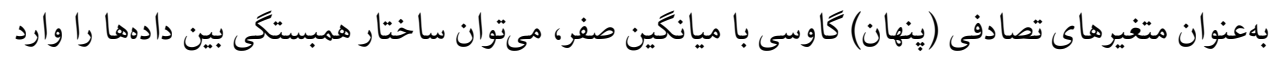
مدل كرد.

ج- اثرات فضايى: اخر (s) يك متغير تصادفى فضايى باشد، با تعريف for

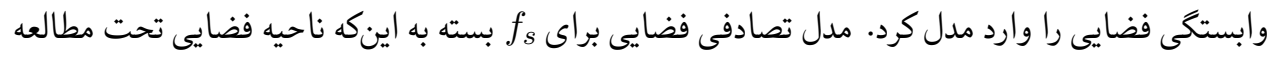

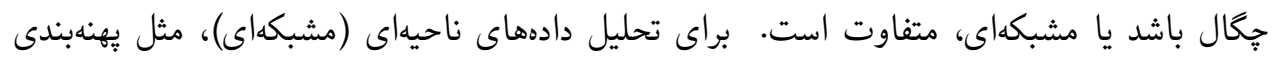

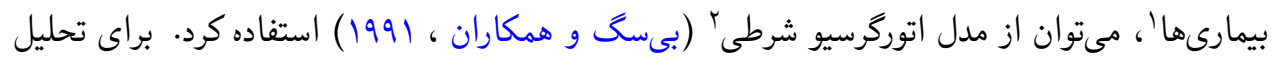

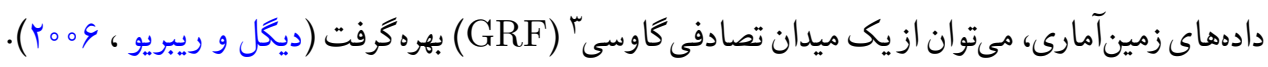

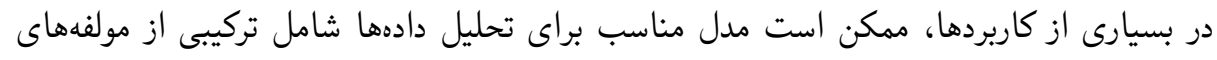

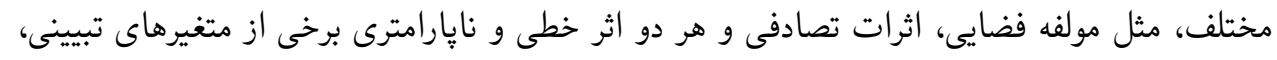

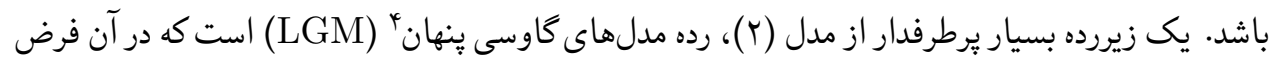

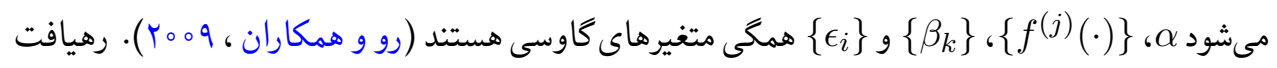

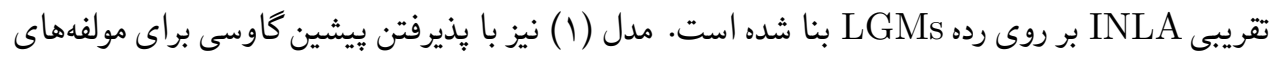

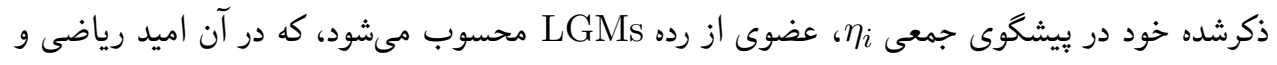

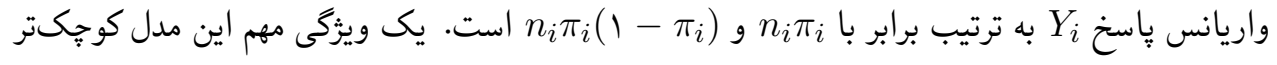

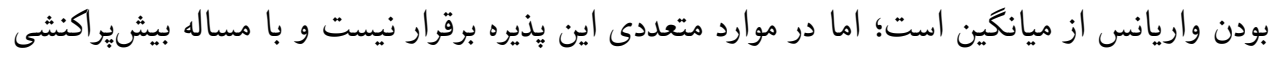

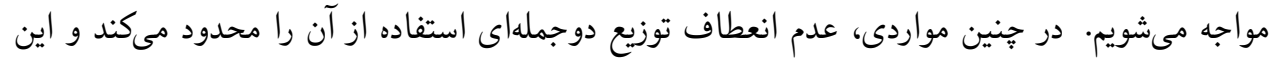

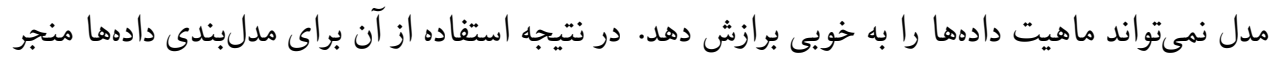

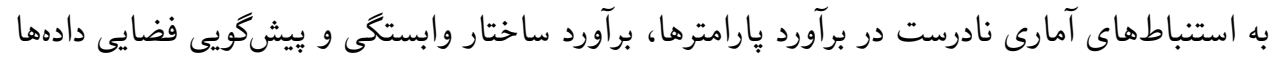

\footnotetext{
${ }^{1}$ Disease mapping

${ }^{2}$ Conditional autoregressive

${ }^{3}$ Gaussian Random Field

${ }^{4}$ Latent Gaussian Models
} 


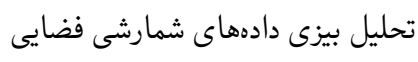

MIT

مىشود. مدل جانشين براى رفح مشكل مطرحشده، مدل منعطف بتا-دوجملهاى فضايى است. اين مدل

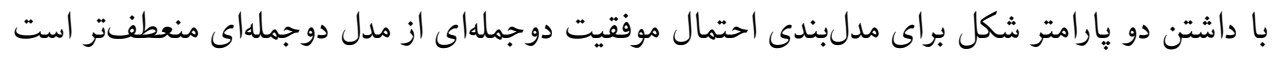

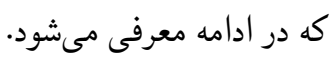

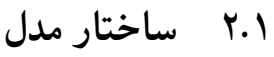

فرض كنيد

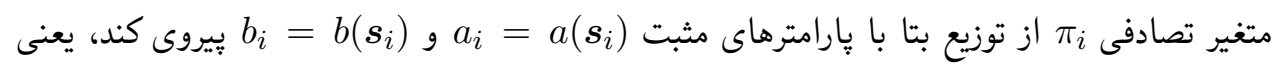

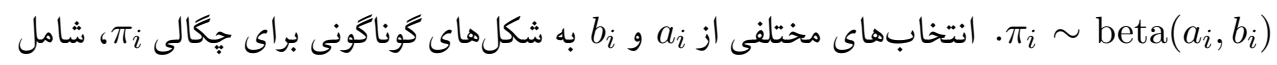

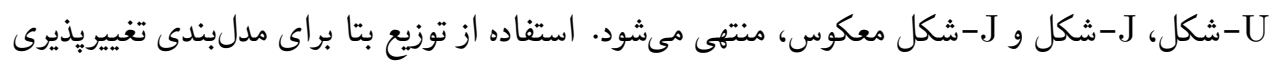

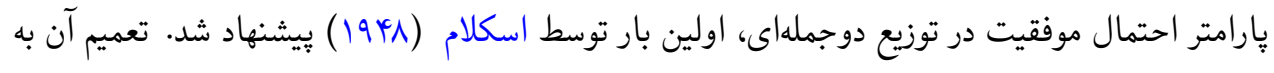

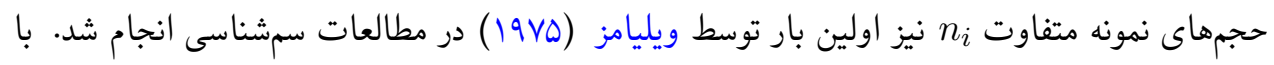

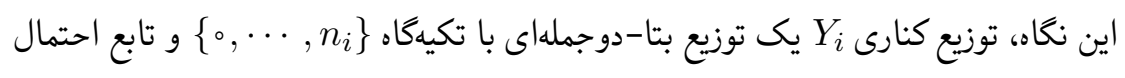

$$
\mathrm{P}\left(Y_{i}=y_{i} \mid a_{i}, b_{i}\right)=\left(\begin{array}{c}
n_{i} \\
y_{i}
\end{array}\right) \frac{\operatorname{Beta}\left(a_{i}+y_{i}, n_{i}+b_{i}-y_{i}\right)}{\operatorname{Beta}\left(a_{i}, b_{i}\right)}
$$

است، كه در آن (, Beta تابع بتا است. با شرط معلوم بودن

$$
\mathrm{E}\left(Y_{i}\right)=n_{i} \frac{a_{i}}{a_{i}+b_{i}}, \quad \operatorname{Var}\left(Y_{i}\right)=\frac{n_{i} a_{i} b_{i}\left(n_{i}+a_{i}+b_{i}\right)}{\left(a_{i}+b_{i}\right)^{\curlyvee}\left(1+a_{i}+b_{i}\right)}
$$

هستند، كه بر اساس آنها، توسعه يك خارجوب ركرسيون فضايى براى مدلبندى پارامترهاى

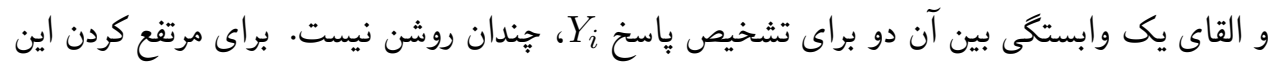

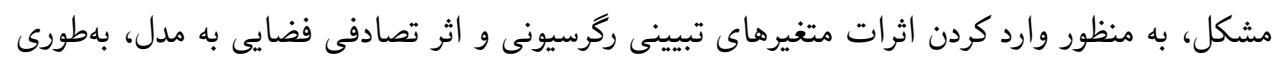

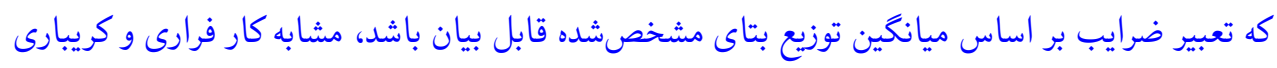

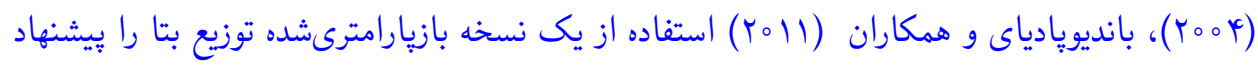

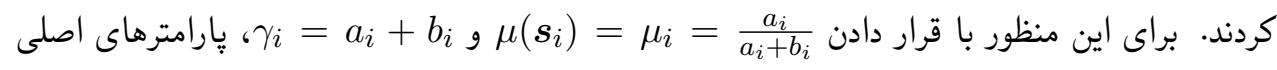
توزيع بتا براى $\pi_{i}$ بهصورت $Y_{i} \sim$ beta $\left(\mu_{i} \gamma_{i},\left(1-\mu_{i}\right) \gamma_{i}\right)$ 
ن.betabin $\left(n_{i}, \mu_{i} \gamma_{i},\left(1-\mu_{i}\right) \gamma_{i}\right)$ نيز مىتوان براى بيوند $\mu_{i}$ به بيشكوى

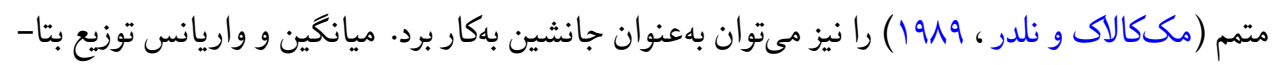
دوجملهاى بازيارامترىشده حاصل عبارتند از با مقايسه واريانسهاى دو مدل دوجملهاى و بتا-دوجملهاى، معلوم مىشود كه (1,

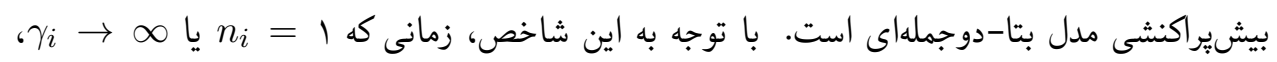

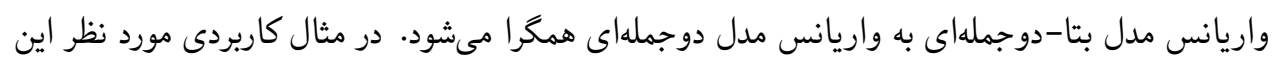

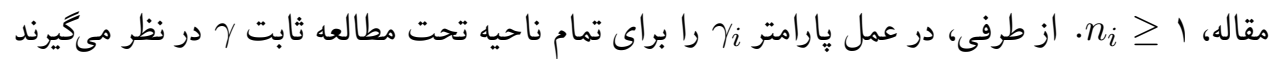

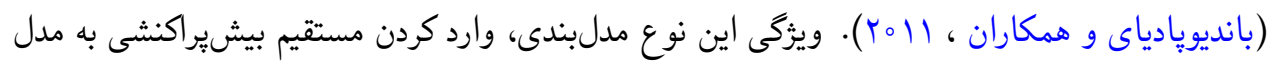

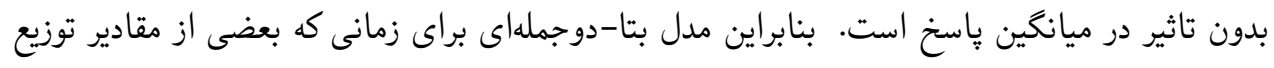

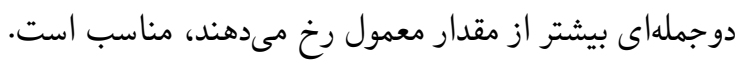

\section{r تحليل بيزى مدل بتا-دوجملهاى}

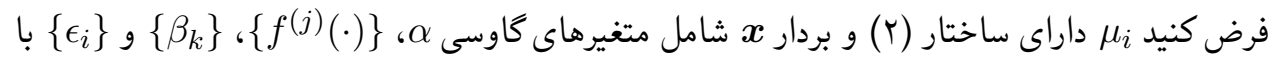

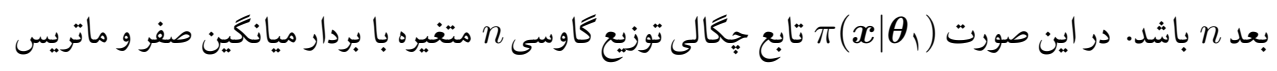
دقت (Q)

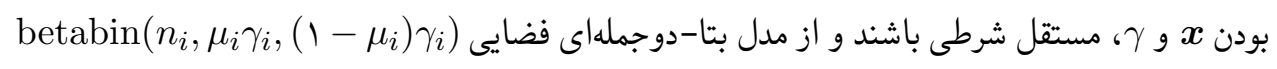

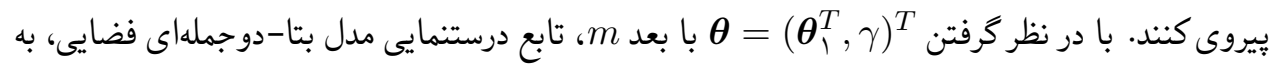

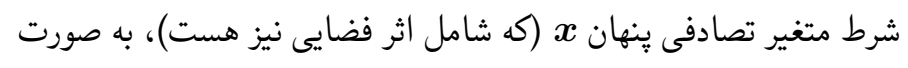

$$
\mathrm{L}(\boldsymbol{\theta} \mid \boldsymbol{x}, \boldsymbol{y})=\prod_{i=1}^{n_{d}}\left[\left(\begin{array}{l}
n_{i} \\
y_{i}
\end{array}\right) \frac{\left[\prod_{k=0}^{y_{i}-1}\left(\gamma \mu_{i}+k\right)\right]\left[\prod_{k=0}^{n_{i}-y_{i}-1}\left(\gamma\left(1-\mu_{i}\right)+k\right)\right]}{\prod_{k=0}^{n_{i}-1}(\gamma+k)}\right]
$$

است، كه در آن براى هر r حقيقى مثبت، إن

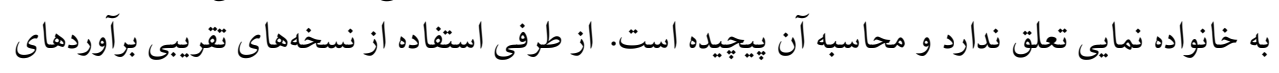




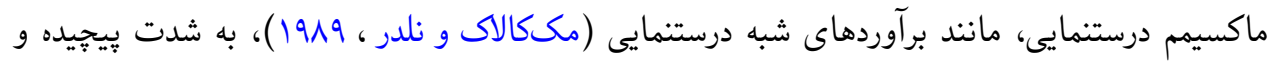

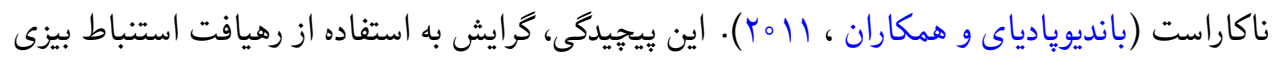

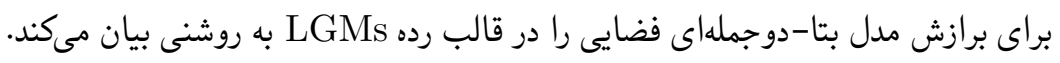

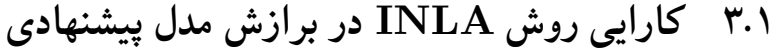

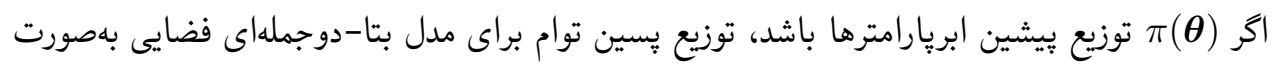

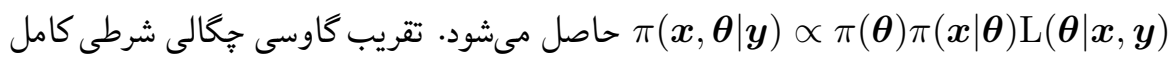

$$
\pi(\boldsymbol{x} \mid \boldsymbol{\theta}, \boldsymbol{y}) \propto \exp \left\{-\frac{1}{\mathrm{r}} \boldsymbol{x}^{T} Q\left(\boldsymbol{\theta}_{\uparrow}\right) \boldsymbol{x}+\sum_{i=1}^{n_{d}} g_{i}\left(x_{i}\right)\right\}
$$

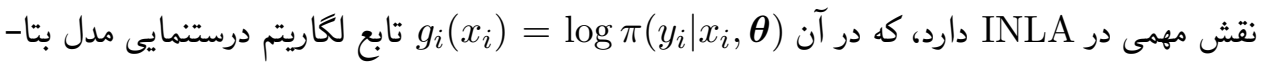

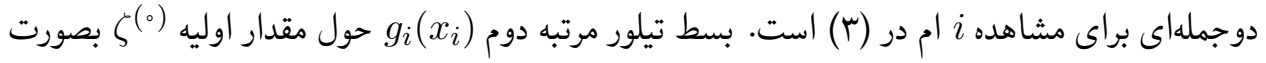

$$
g_{i}\left(x_{i}\right) \approx g_{i}\left(\zeta^{(\circ)}\right)+c_{i} x_{i}-\frac{1}{r} d_{i} x_{i}^{r}
$$

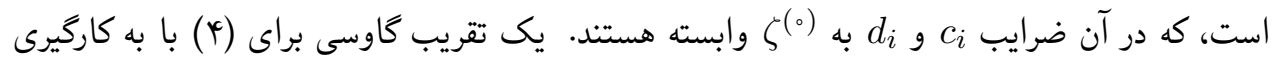
ماتريس دقت

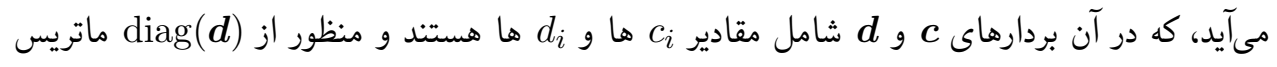

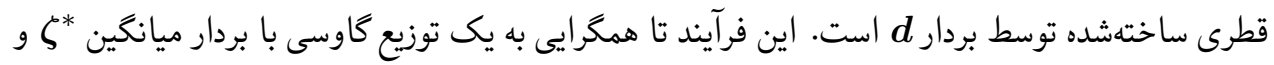
ماتريس دقت

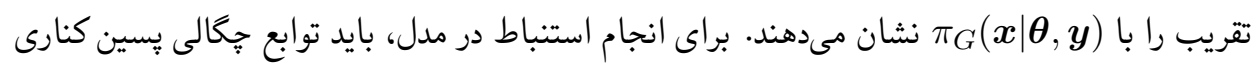

$$
\begin{aligned}
& \pi\left(x_{i} \mid \boldsymbol{y}\right)=\int \pi\left(x_{i} \mid \boldsymbol{\theta}, \boldsymbol{y}\right) \pi(\boldsymbol{\theta} \mid \boldsymbol{y}) d \boldsymbol{\theta}, \quad i=1, \ldots, n \\
& \pi\left(\theta_{j} \mid \boldsymbol{y}\right)=\int \pi(\boldsymbol{\theta} \mid \boldsymbol{y}) d \boldsymbol{\theta}_{-j}, \quad j=1, \ldots, m
\end{aligned}
$$




$$
\begin{aligned}
& \text { را تقريبى بهدست آورد، كه در آن ز- } \\
& \left.\tilde{\pi}(\boldsymbol{\theta} \mid \boldsymbol{y}) \propto \frac{\pi(\boldsymbol{x}, \boldsymbol{\theta}, \boldsymbol{y})}{\pi_{G}(\boldsymbol{x} \mid \boldsymbol{\theta}, \boldsymbol{y})}\right|_{\boldsymbol{x}=\boldsymbol{x}^{*}(\boldsymbol{\theta})}
\end{aligned}
$$

تقريب زده مىشود، كه در آن (A)

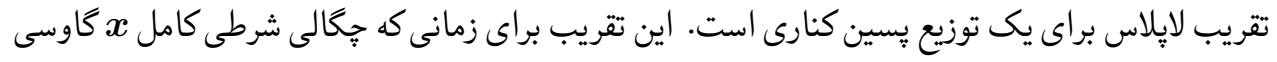

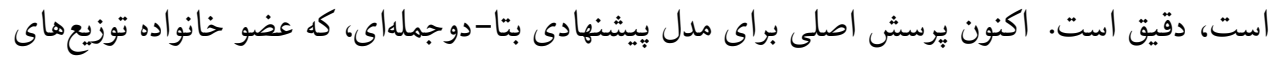
نمايى هم نيست، اطمينان از امكان اجراى كاراى روش

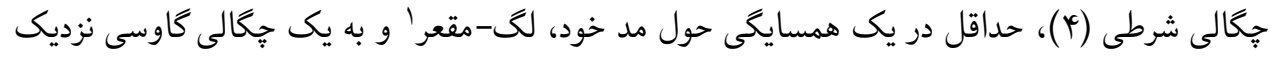

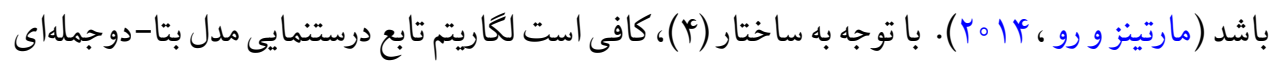

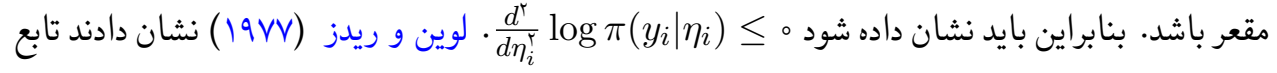

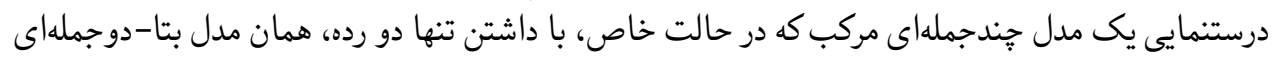

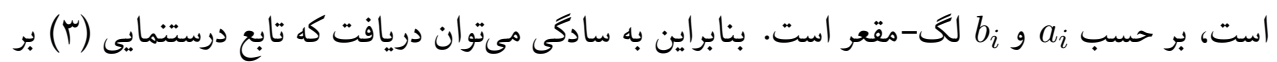
حسب $\mu_{i}$ لع-مقعر است. با توجه به اينكه تابع ييوند لجيت $)=\ln \left(\frac{\mu_{i}}{1-\mu_{i}}\right)$

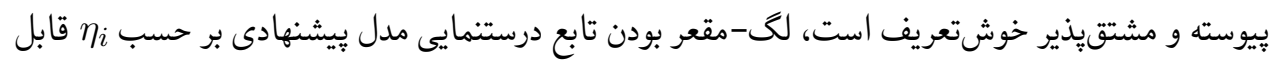

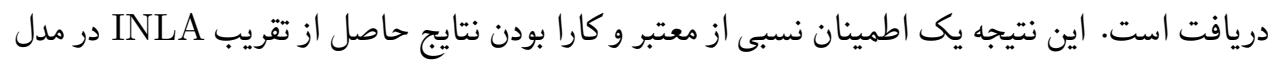

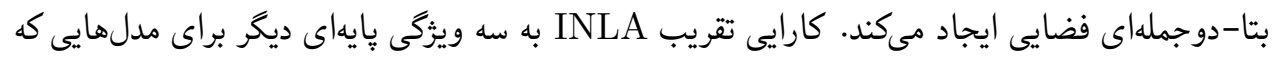

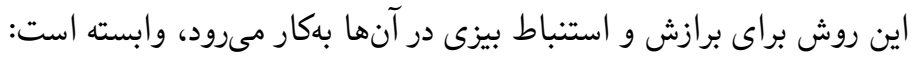

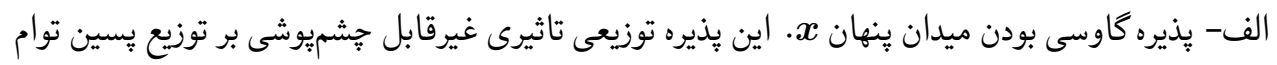
مدل دارد. ب- ويثگى ماركوفى يا همان استقلال شرطى ميدان تصادفى ينهان x مارد، كه اغلب داراى بعد بزركى در

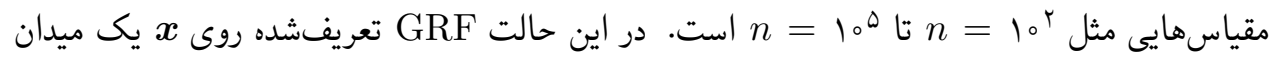

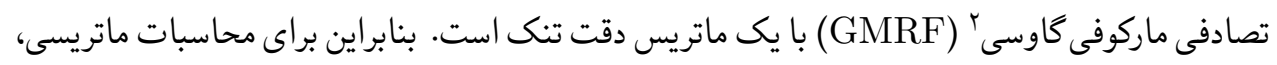

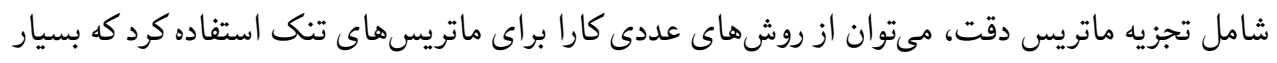

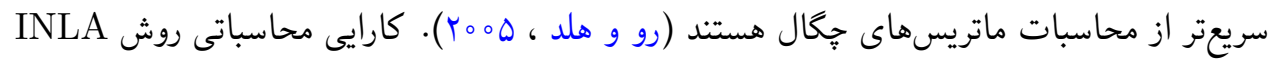

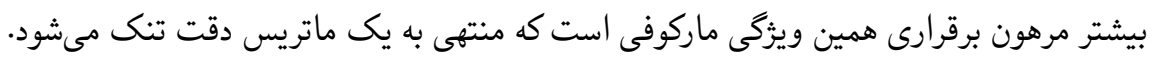




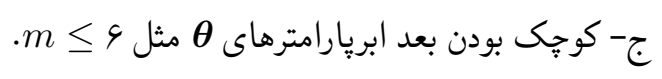

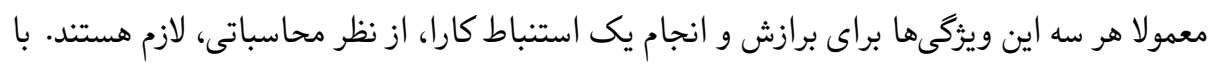

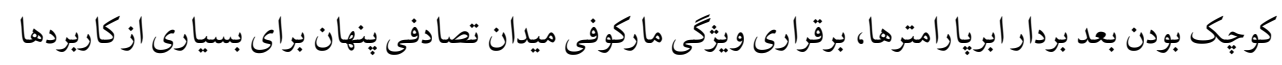

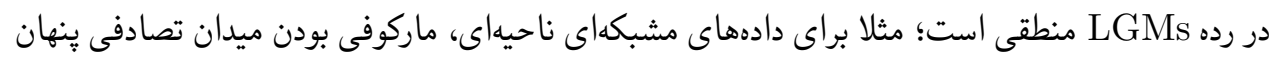

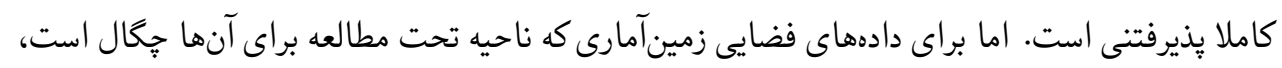

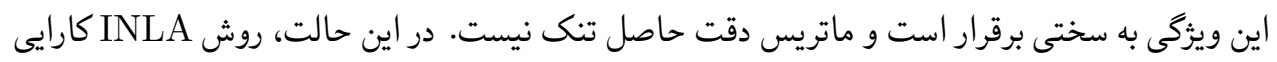

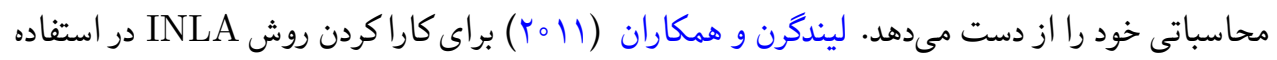

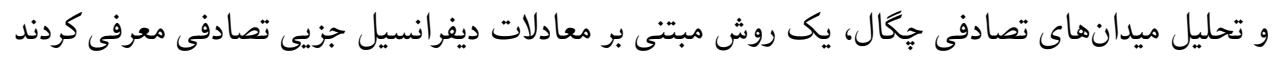

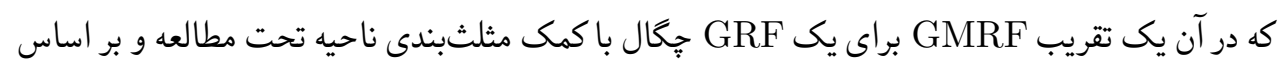

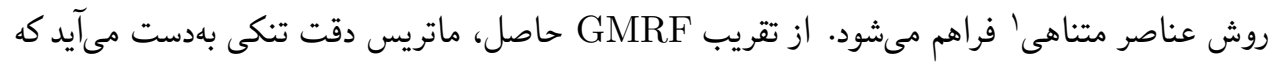

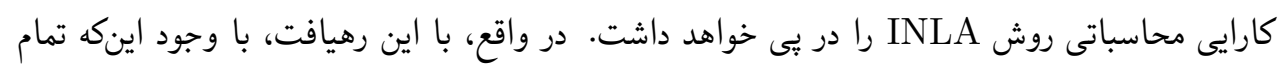

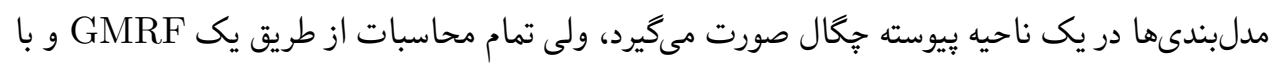

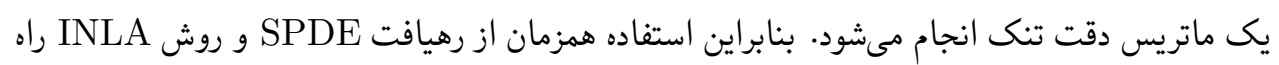

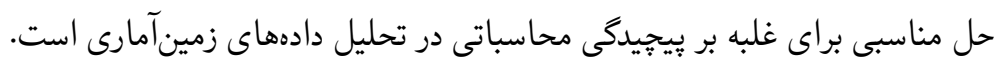

\section{SPDE}

فرض كنيد

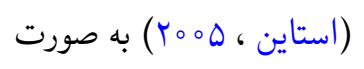

$$
C(\boldsymbol{h})=\frac{\sigma^{\curlyvee}}{r^{\nu-1} \Gamma(\nu)}(\kappa\|\boldsymbol{h}\|)^{\nu} K_{\nu}(\kappa\|\boldsymbol{h}\|)
$$

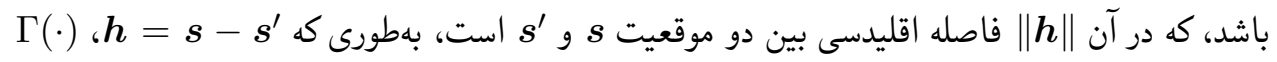

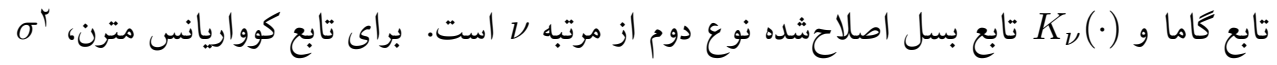

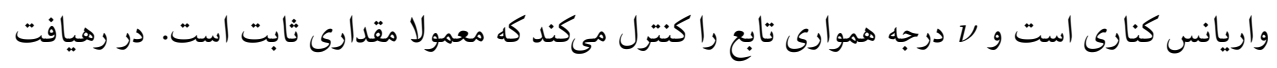

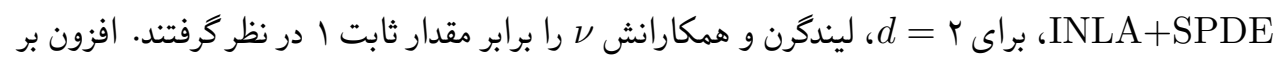

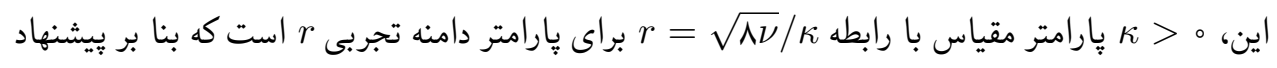




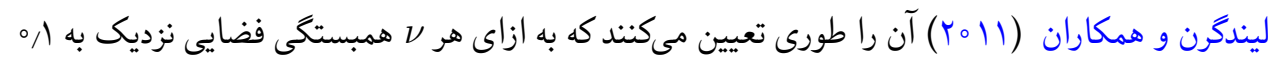

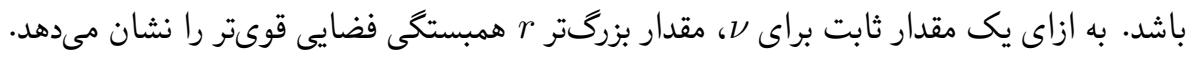

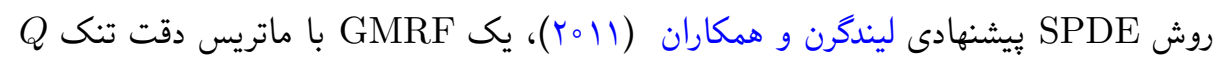

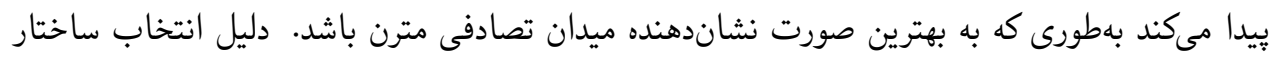

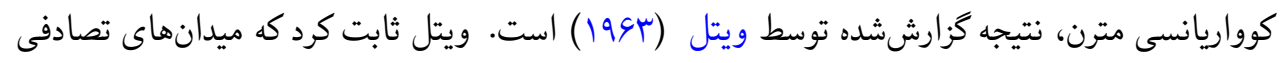

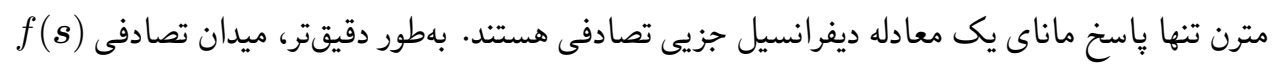

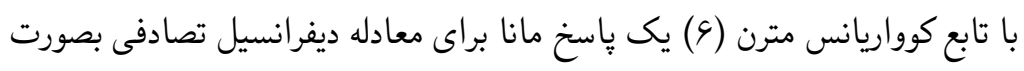

$$
\left(\kappa^{r}-\triangle\right)^{\frac{\zeta}{r}}(\tau f(s))=\Omega(s), \quad s \in D \subseteq \Re^{d}
$$

است، كه در آن ه عملكر ديفرانسيلى مرتبه دوم يا همان عملكر لايلاس است، ح واريانس راكنترل مىكند

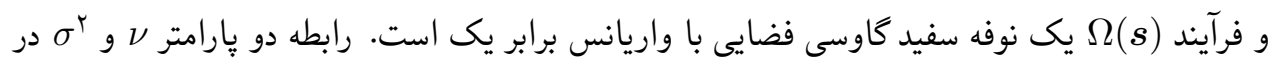

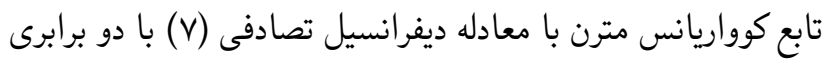

$$
\zeta=\nu+d / r, \quad \sigma^{r}=\frac{\Gamma(\nu)}{\Gamma(\zeta)(\boldsymbol{r} \pi)^{d / \Upsilon} \kappa^{\Upsilon \nu} \tau^{\curlyvee}}
$$

مشخص مىشود. براى بهدست آوردن يك GMRF بايد يك مقدار صحيح براى ك انتخاب شود. با در نظر گرفتن ا

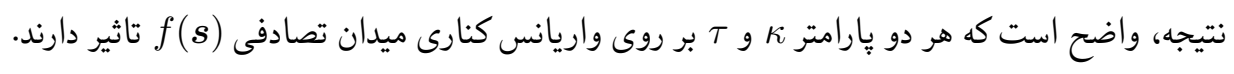

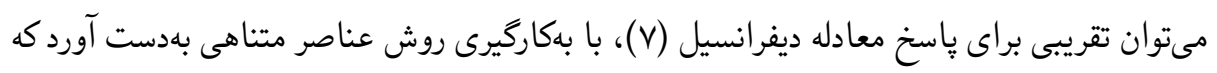

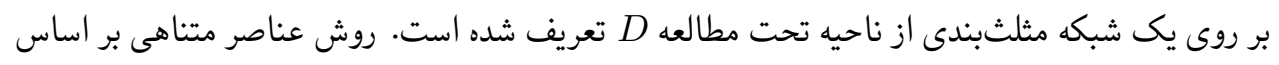

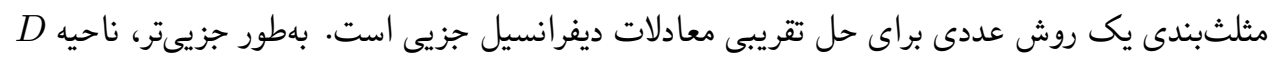

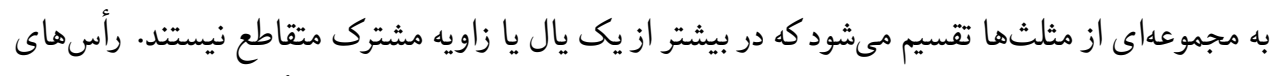

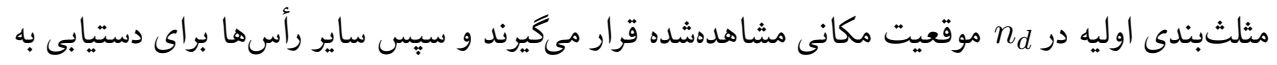

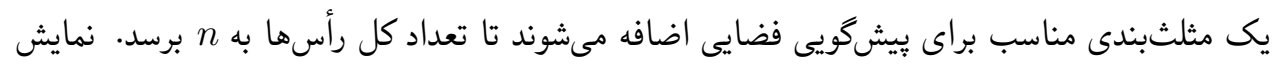
تقريب عناصر متناهى معادله (V) بهصورت تصادفى با توزيع كاوسى هستند و به شكلى انتخاب مىشوند كه توزيع (s)

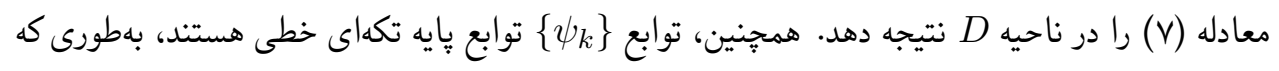




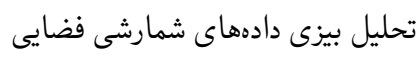

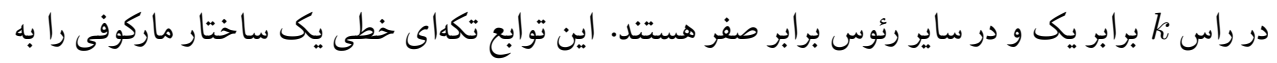

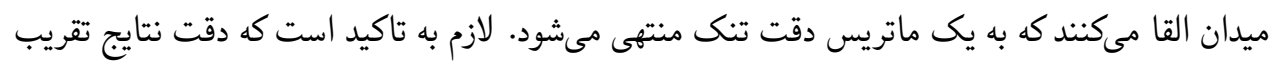

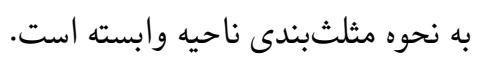

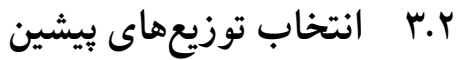

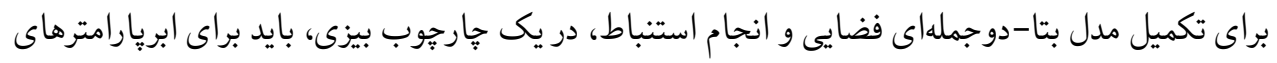

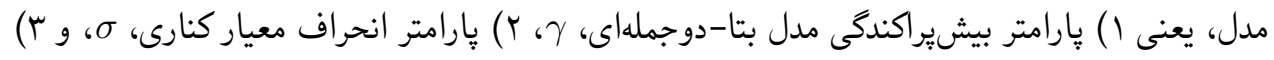

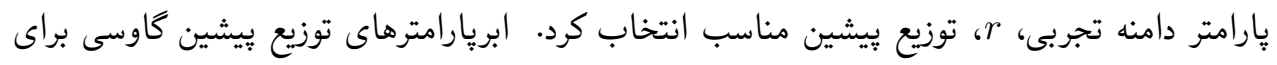

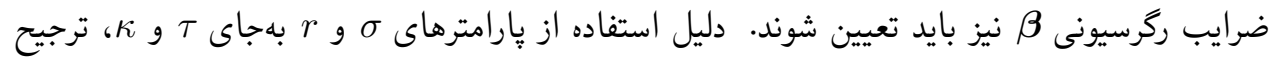

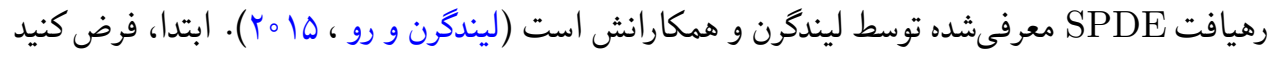

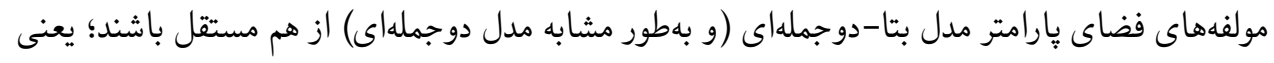

$$
\pi(\boldsymbol{\beta}, \gamma, \sigma, r)=\pi(\boldsymbol{\beta}) \pi(\gamma) \pi(\sigma) \pi(r) .
$$

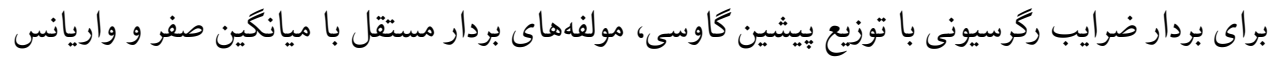

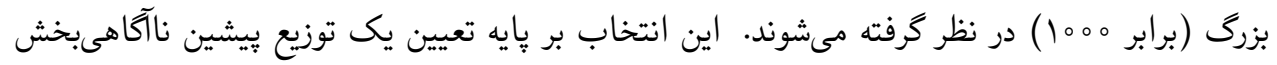

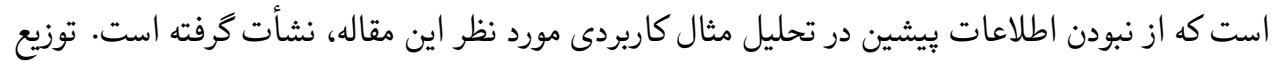

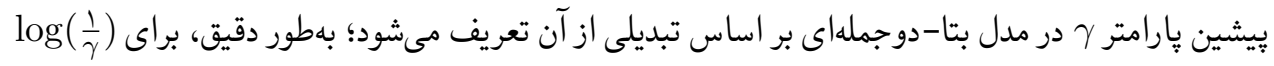

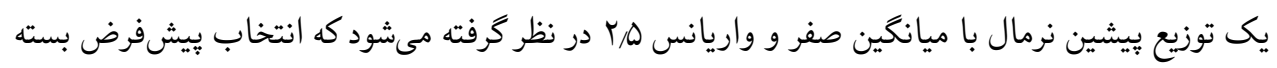

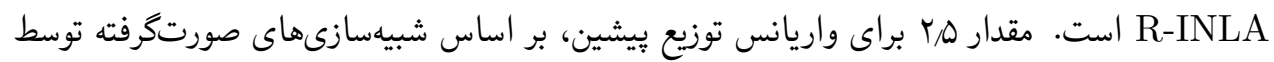

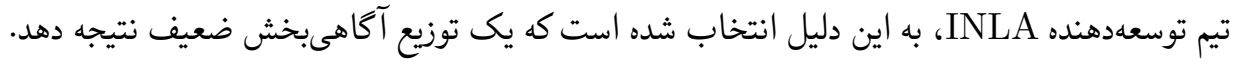

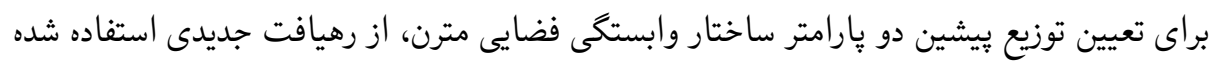

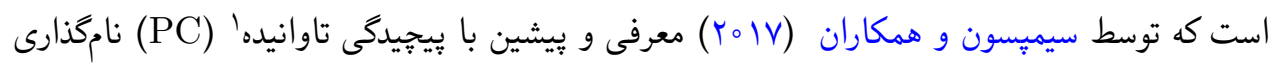

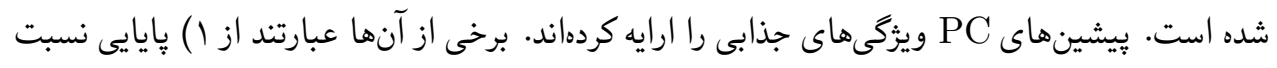

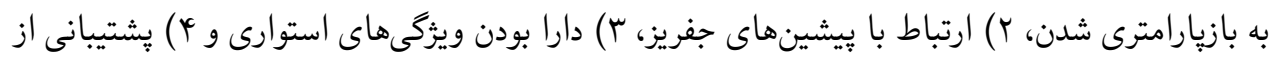

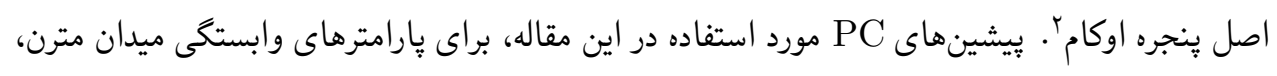

${ }^{1}$ Penalized Compelxity

${ }^{2}$ Occam's razor 


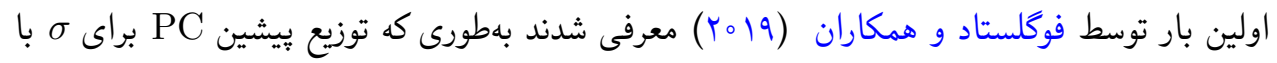

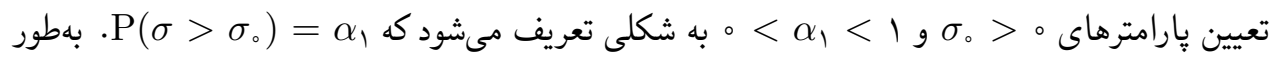

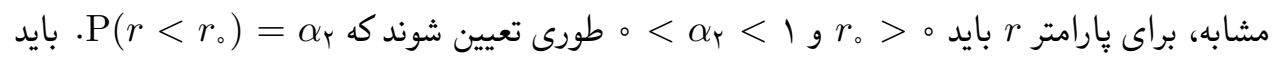

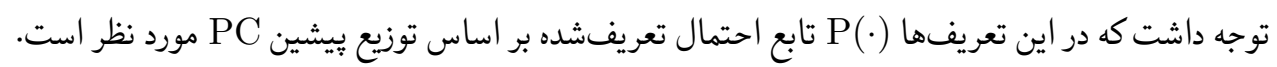

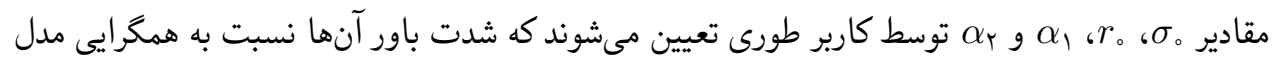

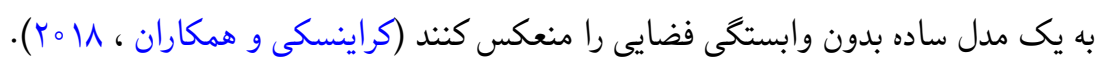

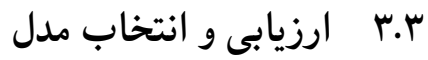

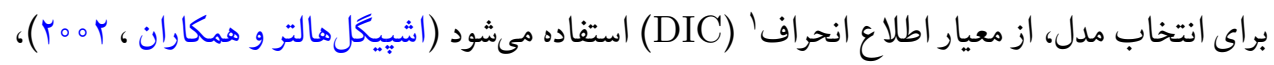

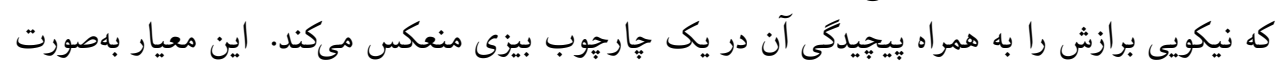
تعريف مىشود، كه در آن (⿻) DIC $=\bar{D}+p_{D}$

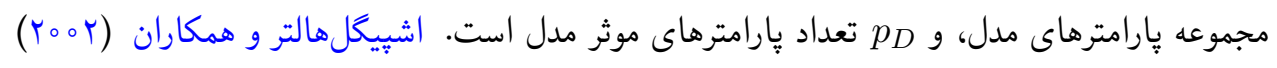

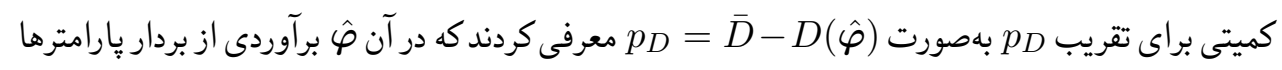

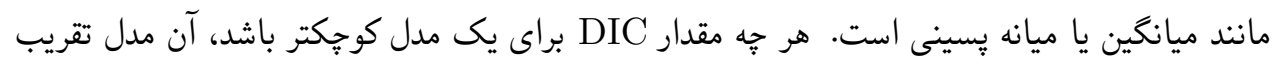
بهترى از مدل واقعى است كه دادها از آن توليد شدهاند.

اخرجه DIC معيارى براى سنجش نسبى نيكويى برازش در بين مدلهاى رقيب است، اما اطلاعى از مداز

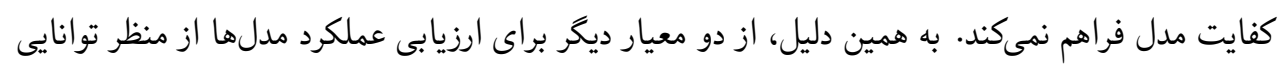

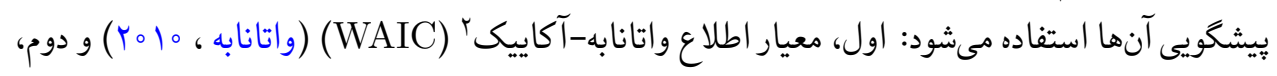

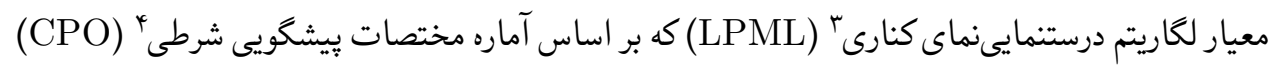

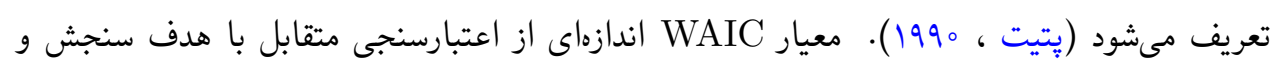

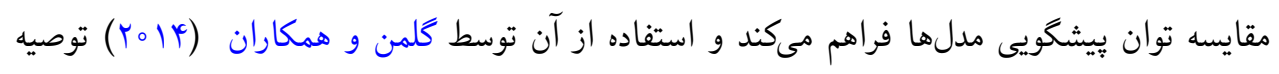

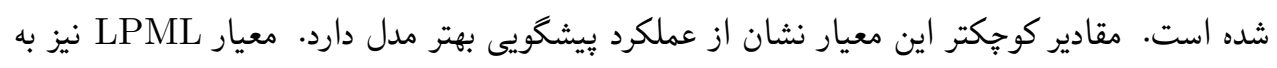

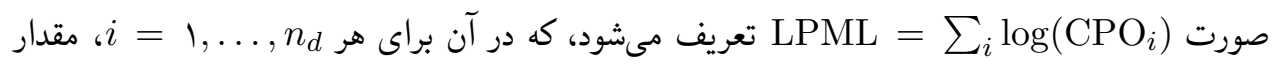
$i$ احتمال بِينى مشاهده $\mathrm{CPO}_{i}=\pi\left(y_{i} \mid \boldsymbol{y}_{-i}\right)$

${ }^{1}$ Deviance Information Criterion

${ }^{2}$ Watanabe-Akaike Information Criterion

${ }^{3}$ Log Pseudo-Marginal Likelihood

${ }^{4}$ Conditional Predictive Ordinate 


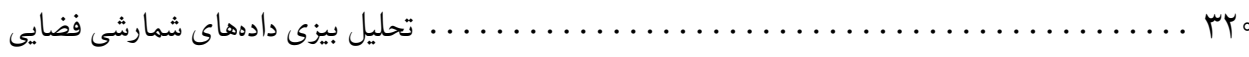

ام برازش شده است، نشان مىدهد. با اين تفسير، مقادير بزرختر معيار LPML يشتيبانى بهتر مدل از دادهاى مشاهدهده را نشان مىدهند.

\section{P}

به منظور ارزيابى مدل بتا-دوجملهاى فضايى، يك مطالعه شبيهسازى انجام شد. با اين فرض كه (s)

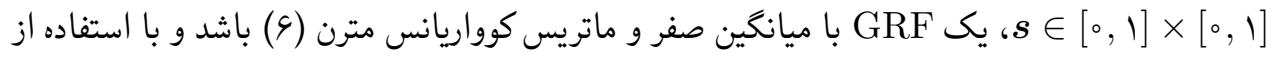
نمايش SPDE در (V)، يك تحقق به حجم

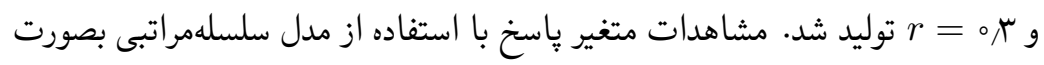

$$
\begin{aligned}
\left(u\left(\boldsymbol{s}_{\backslash}\right), \ldots, u\left(\boldsymbol{s}_{n_{d}}\right)\right) & \sim \mathrm{N}(\circ, \Sigma) \\
\operatorname{logit}\left(\mu\left(\boldsymbol{s}_{i}\right)\right) & =\beta_{\circ}+\beta_{\uparrow} z\left(\boldsymbol{s}_{i}\right)+u\left(\boldsymbol{s}_{i}\right) \\
\pi\left(\boldsymbol{s}_{i}\right) & \sim \operatorname{beta}\left(\gamma \mu\left(\boldsymbol{s}_{i}\right), \gamma\left(1-\mu\left(\boldsymbol{s}_{i}\right)\right)\right) \\
Y_{i}\left(\boldsymbol{s}_{i}\right) & \sim \operatorname{bin}\left(n\left(\boldsymbol{s}_{i}\right), \pi\left(\boldsymbol{s}_{i}\right)\right)
\end{aligned}
$$

توليد شدند، كه در آن ماتريس كوواريانس ع از تقريب SPDE ميدان مترن (ليندكرن و همكاران ،

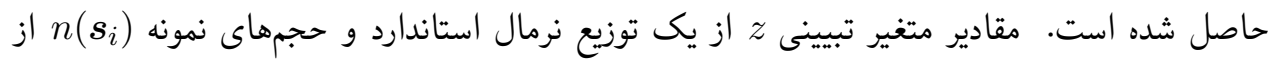

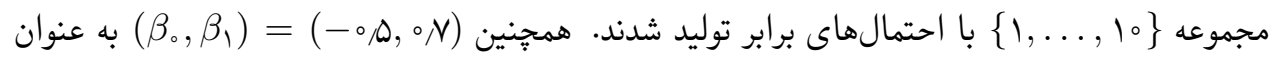
مقادير واقعى ضرايب ركرسيونى انتخاب شدند.

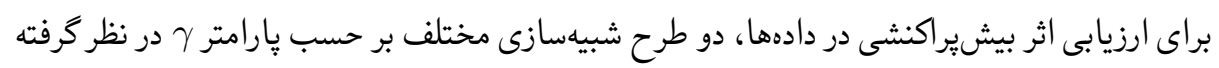

طرح اول- مدل با بيشيراكنشى بزرگ كه در آن مقدار واقعى براى يارامتر ح برابر ب تعيين شد. با اين

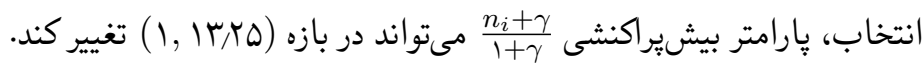

طرح دوم- مدل نزديك به دوجملهاى كه در آن مقدار واقعى براى يارامتر ح برابر هه انتخاب شد. در اين

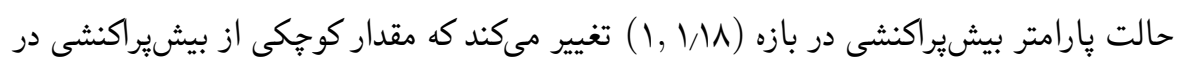
ياسخ را در نظر مى خيرد. 
براى محاسبه معيارهاى ارزيابى مدل، م Yo مجموعه داده براى هر طرح شبيهسازى شدند. به هر مجموعه

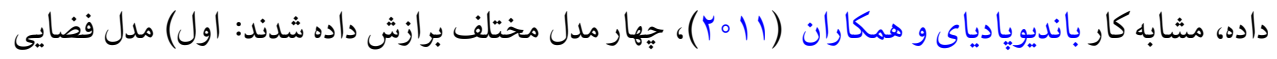

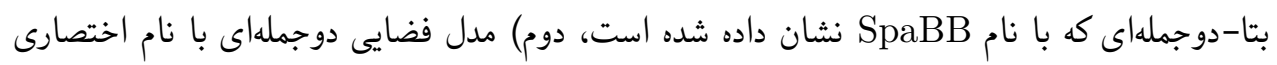
SpaBin

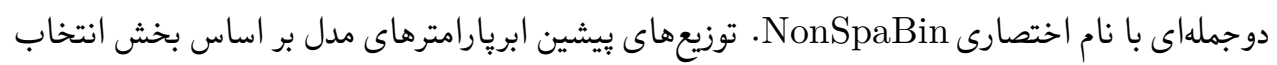

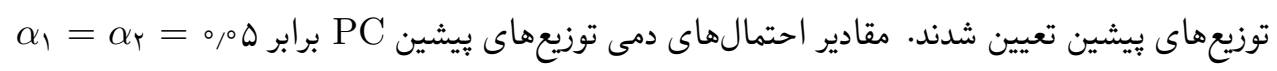
و

$$
\text { نرمافزار R و به كمك بسته نرمافزارى R-INLA و مهامه انجام شده است. }
$$

براى هر مدل، معيارهاى DIC و DPML محاسبه شدند كه به ترتيب نمودار جعبهاى آنها در شكلهاى ا و Y نمايش داده شدهاند. براى برآوردهاى يارامترهاى مدل، قدر مطلق اريبى نسبى، ميانكين

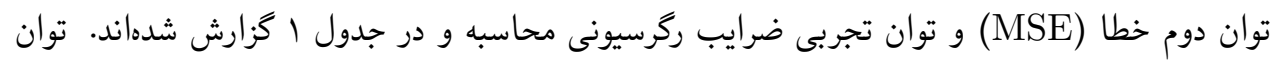

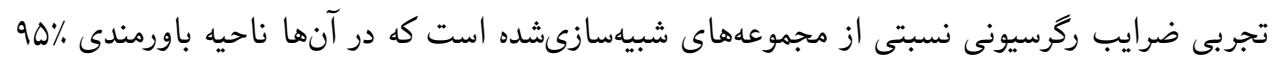

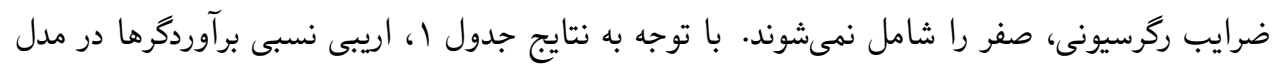

\begin{tabular}{|c|c|c|c|c|c|c|}
\hline \multicolumn{2}{|c|}{ توان تجربى } & \multicolumn{3}{|c|}{ اريبى نسبى (MSE) } & \multirow[t]{2}{*}{ مدل } & \multirow[t]{2}{*}{ طرح } \\
\hline$\beta_{1}$ & $\beta_{0}$ & $\gamma$ & $\beta_{1}$ & $\beta_{\circ}$ & & \\
\hline$\circ 9 V^{k}$ & 0,094 & $(1,9 \circ \%) \circ \circ 11$ & $(0, \wedge \mu G) \circ \circ \Delta 1$ & $(\circ / \wedge ৭ \Lambda) \circ \circ \Delta V$ & SpaBB & اول \\
\hline$\circ 9 V^{*}$ & $0,4+4$ & & $(1, \circ \vee v) \circ, \pi \circ \Delta$ & $\left(1,0 V_{0}\right) \circ \pi / \mu$ & SpaBin & \\
\hline 0.999 & 0,941 & $(1, \pi \mu q) \circ \pi V k$ & $(\circ \vee \wedge \wedge \vee) \wedge \wedge \circ$ & $\left(0, \wedge 4_{0}\right) 0 / 9 \Lambda$ & NonSpaBB & \\
\hline 1,000 & $\circ \wedge \circ \Delta$ & & $(0, \Lambda \circ 0) \circ \lambda \Delta \psi$ & $(0,149) 0 / 109$ & NonSpaBin & \\
\hline 1,000 & 0 0 11 & $(r, \pi, 40) \circ / \Delta 94$ & $(0, \wedge r q) \circ, 0 \mu r$ & $(0,919) 0,00 Y$ & SpaBB & دوم \\
\hline 1,000 & 0,14 & & $(0, \wedge V \Psi) \circ \circ Y \Lambda$ & $(0,9 \Delta 4) 0,094$ & SpaBin & \\
\hline 1,000 & r & $(K \psi, / \Delta \Lambda) \circ / \Lambda \Lambda_{0}$ & $(0, v \wedge v) \circ / 4 q$ & $(0 \wedge r V) \circ \lambda \wedge \varphi$ & NonSpaBB & \\
\hline 1,000 & 0,199 & & $(0, N 9 \mu) \circ / \mu$ & $(0, \Delta+1) \circ / \lambda T$ & NonSpaBin & \\
\hline
\end{tabular}

ملاحظى، در هر دو نوع طرح شبيهسازى، بهجز يك مورد در طرح نوع دوم، از ساير مدلها بهطور قابل

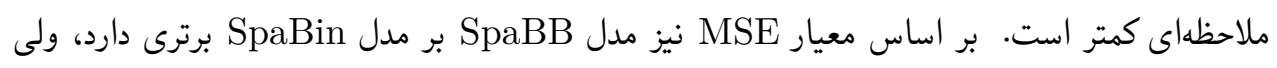

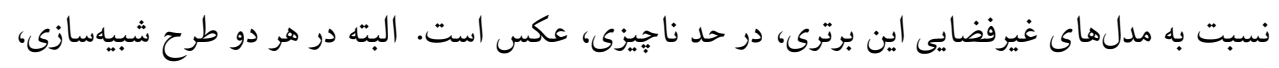

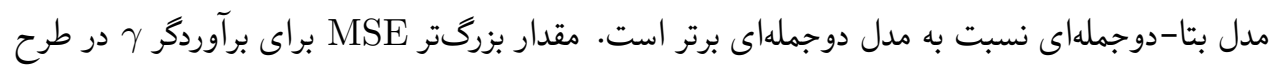

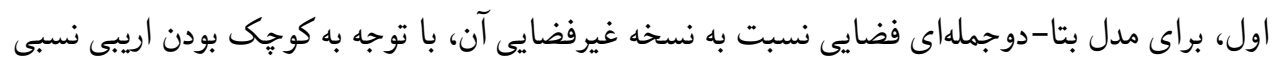

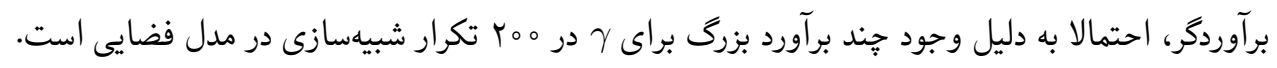

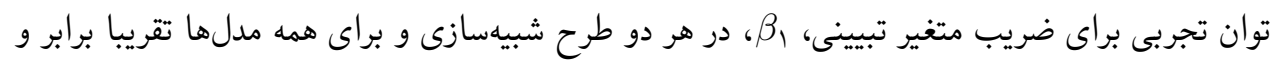




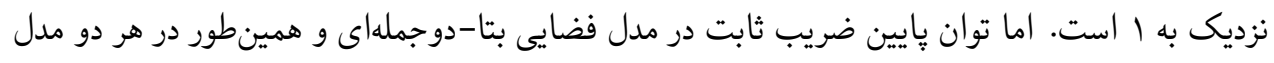

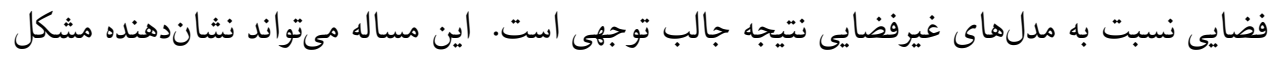

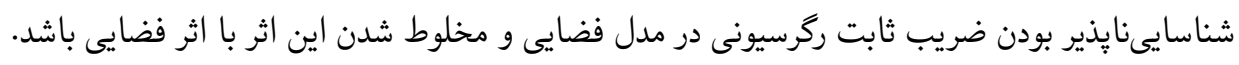

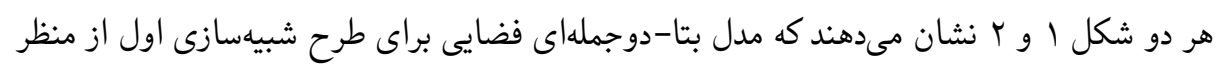

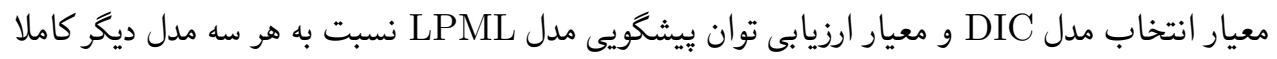

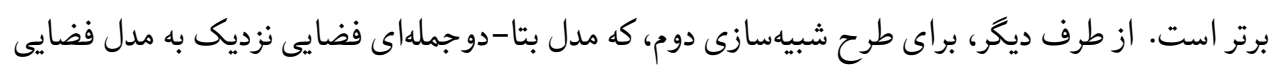

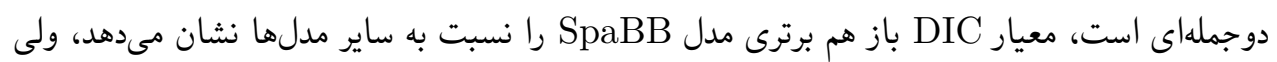

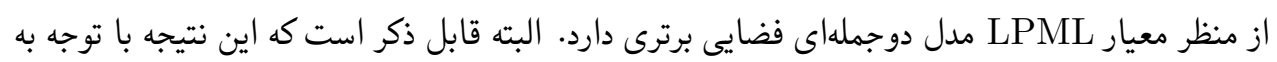

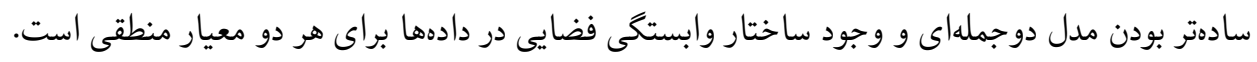

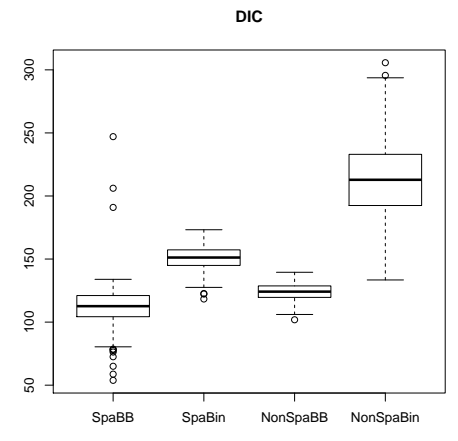

(ب)

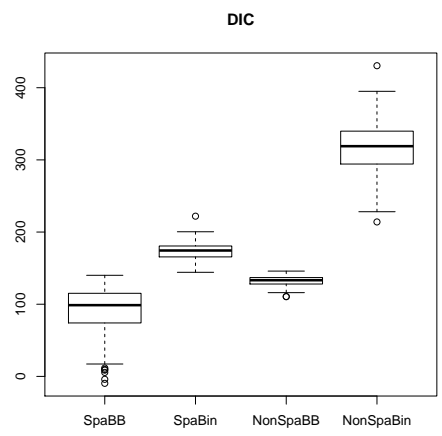

(الف)

شكل ا. مقادير DIC براى دو مدل فضايى دوجملهاى و بتا-دوجملهاى درطرح اول (الف) و دوم (ب) (ب)

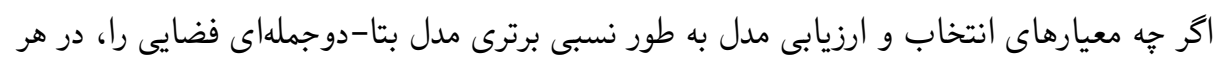

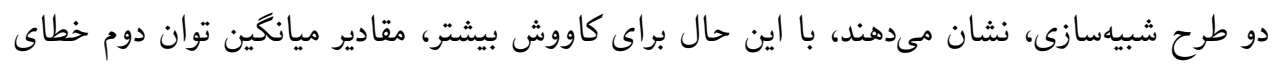

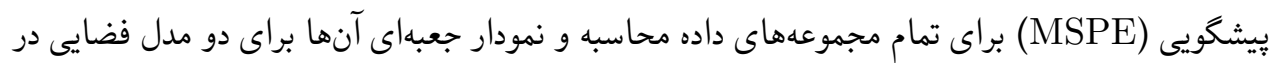

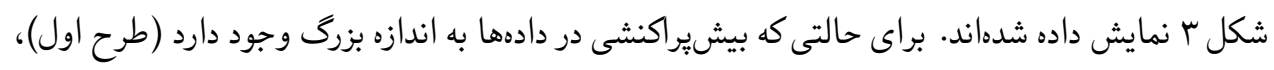

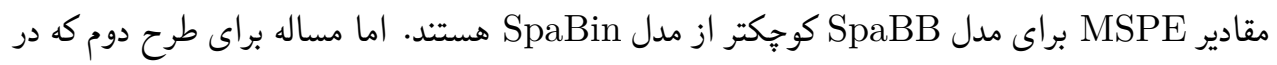

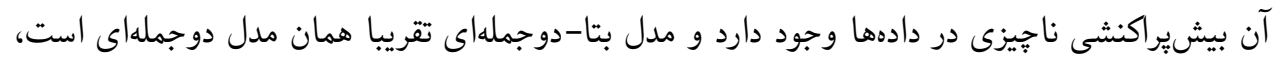

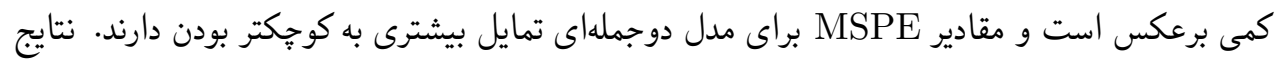

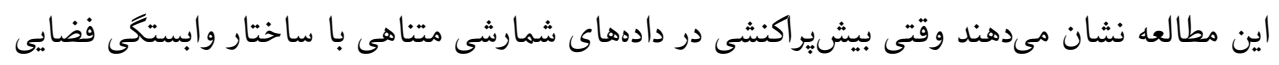



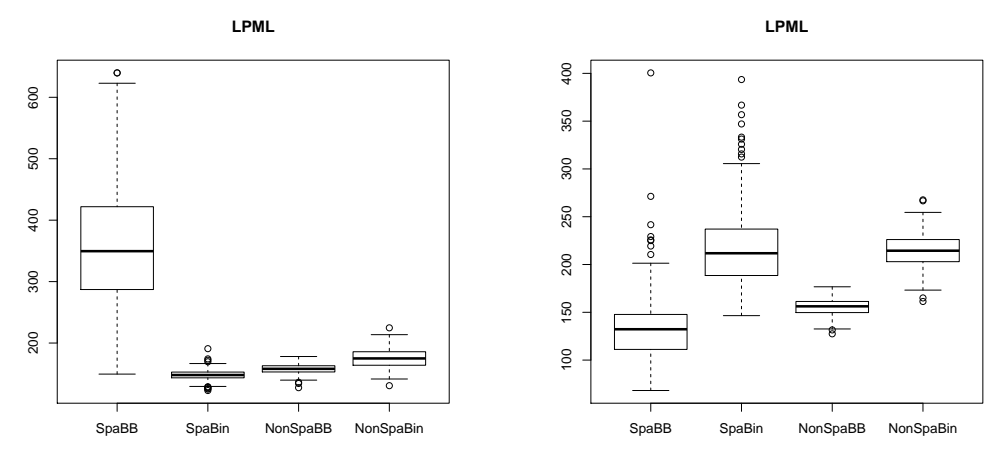

(ب)

(الف)

شكل r. مقادير معيار LPML براى دو مدل فضايى دوجملهاى و بتا-دوجملهاى در طرح اول (الف) و دوم (ب)

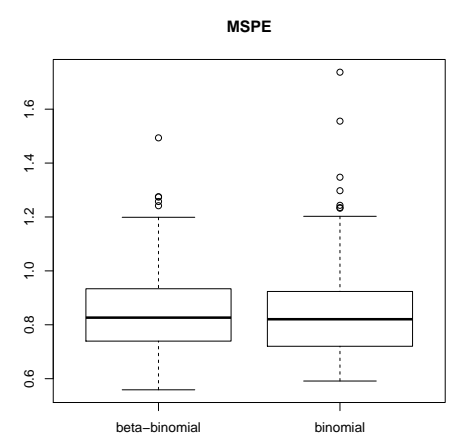

(ب)

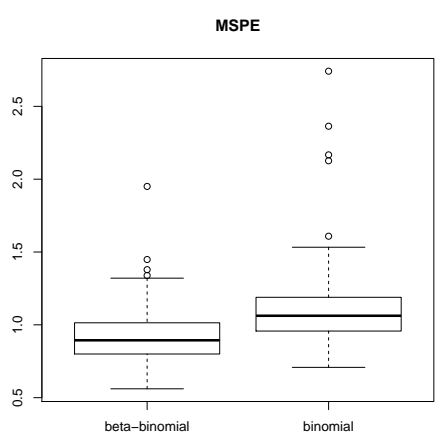

(الف)

شكل r.. مقادير MSPE براى دو مدل فضايى دوجملهاى و بتا-دوجملهاى در طرح اول (الف) و دوم (ب)

وجود دارد، مدل بتا-دوجملهاى فضايى برترى محسوسى نسبت به مدل معمول دوجملهاى فضايى دارد.

\section{ه تحليل دادههاى تصادفهاى منجر به جرح يا فوت}

دادهها مربوط به تصادفهاى منجر به جرح يا فوت در شهرستان مشهد در سال هیم| هستند كه توسط

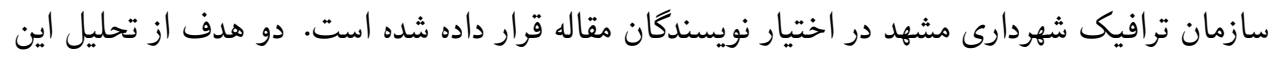

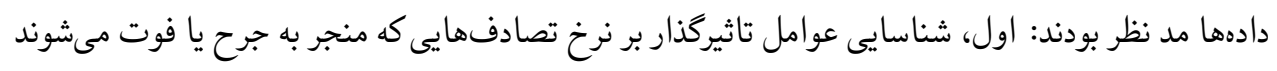


و دوم، تهيه نقشه يهنهبندى از اثر فضايى حاكم بر نرخ اين نوع تصادفها براى شهر مشهد تا بر اساس آن

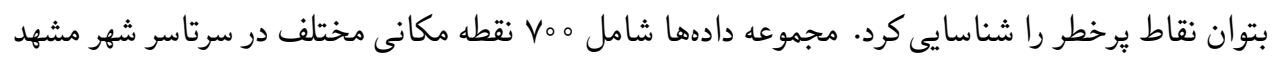

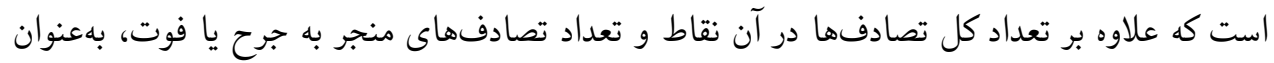

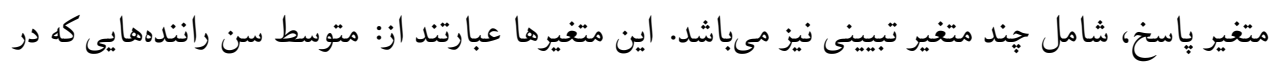

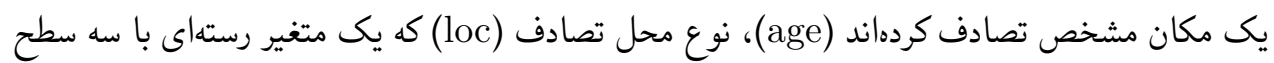

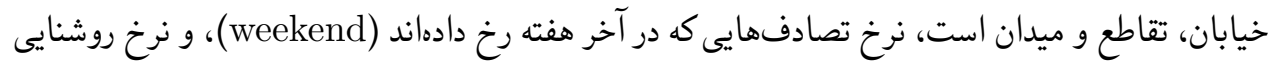

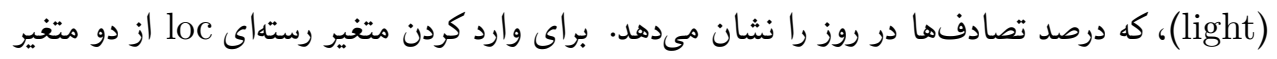

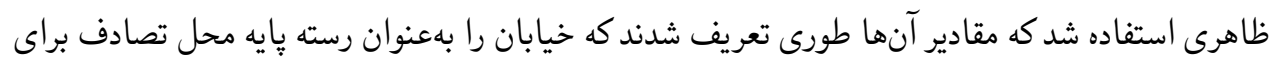

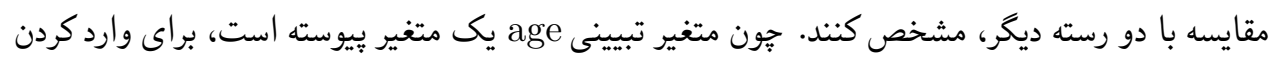

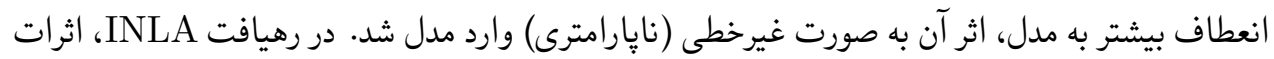

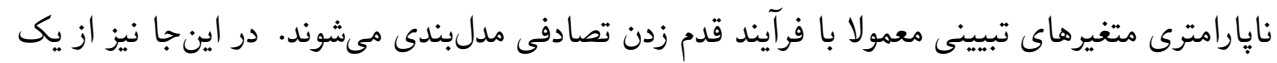

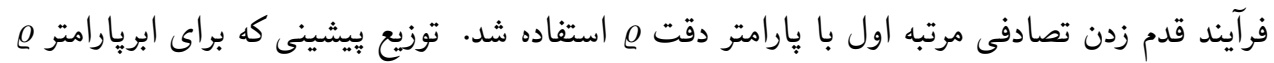

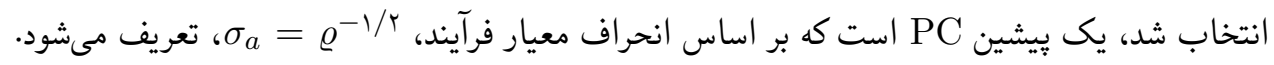
با معلوم بودن a

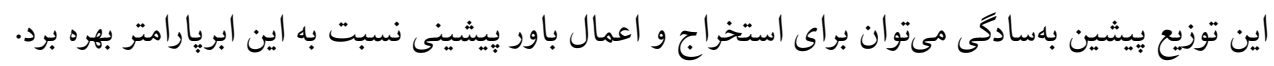

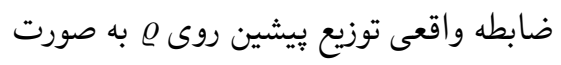
$\pi(\varrho)=\frac{\lambda}{r} \varrho^{-r / r} \exp \left(-\lambda \varrho^{-1 / r}\right), \quad \varrho>\circ$

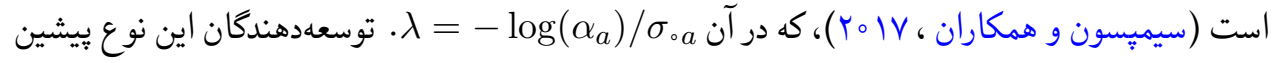

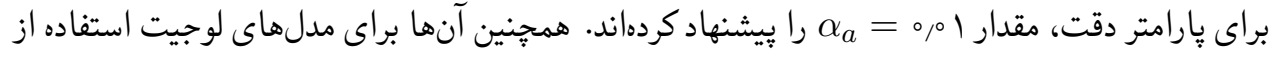

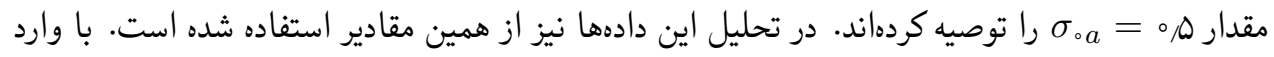

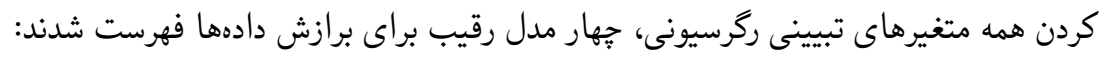

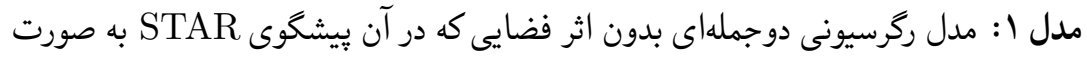

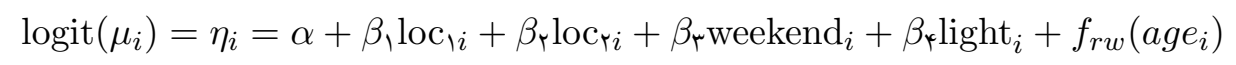




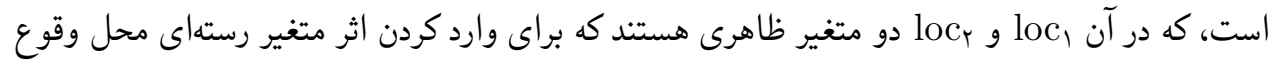
تصادف تعريف شدهاند.

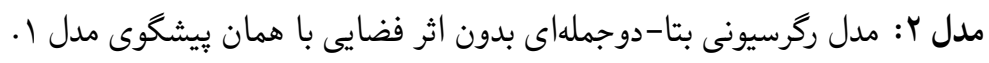

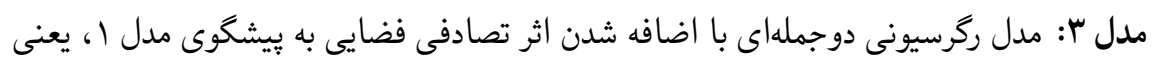

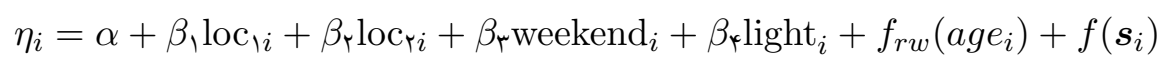

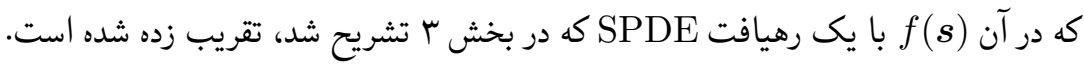

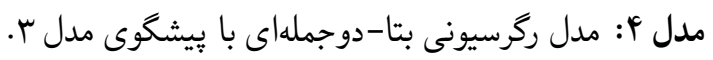

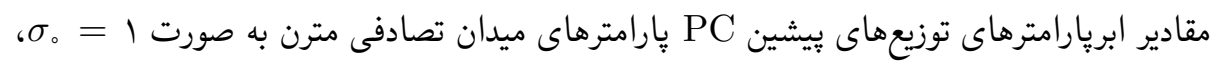

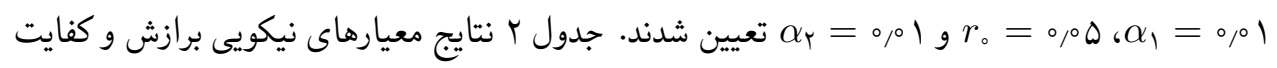

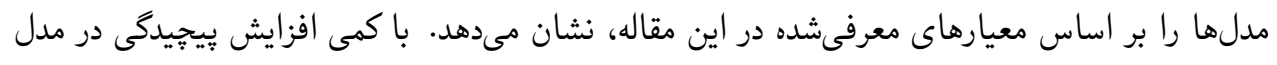

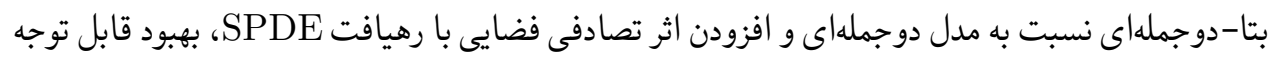

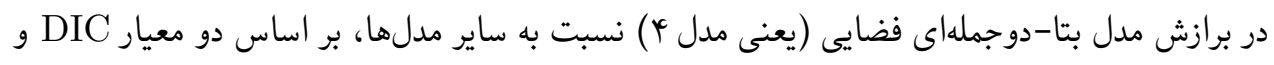
LPML در مورد آن نظر مشخصى داد.

\begin{tabular}{|c|c|c|c|}
\hline \multicolumn{4}{|c|}{ مقايسه مدلها با استفاده از معيارهاى DIC، و و WAIC } \\
\hline LPML & WAIC & DIC & مدل \\
\hline - KYTAYG & $\Delta 40, q 4 i$ & $V+1 / \lambda \varphi_{0}$ & 1 \\
\hline$-k \mu \wedge, \xi \circ \varphi$ & $\Delta 4 \Delta, r q 1$ & $V \circ \Delta, \Delta q r$ & r \\
\hline - Frrpqq & $\Lambda \notin \Leftrightarrow, N \wedge \Delta$ & VET/IVE & r \\
\hline$-\varphi \circ \lambda, \uparrow 9 \Lambda$ & $\Delta 49, \pi q 4$ & $9 \vee 9 / 19 \mathrm{~V}$ & r \\
\hline
\end{tabular}

بهطور دقيقتر، اختلاف مقادير دو معيار DIC و LPML بين مدلهاى ب و † به اندازه كافى بزرگ

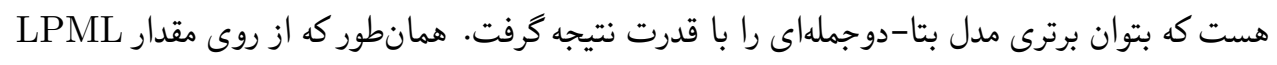

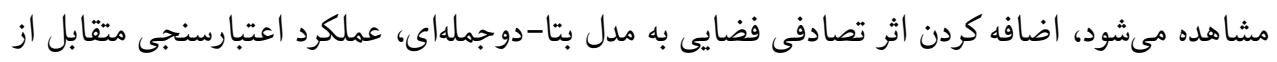

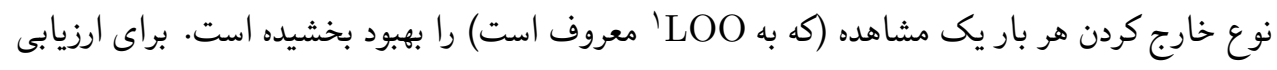

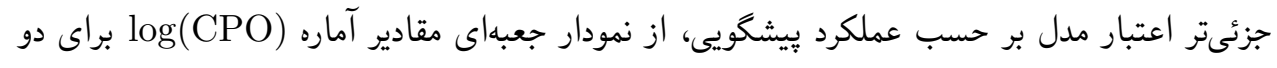




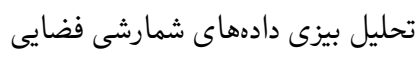

مدل دوجملهاى فضايى و بتا-دوجملهاى فضايى كه در شكل ץ مشاهده مي شود، استفاده شده است. مقادير

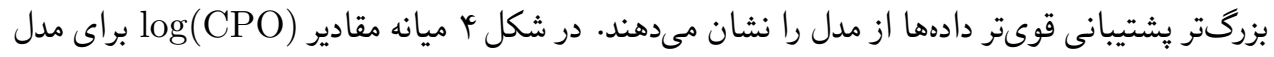

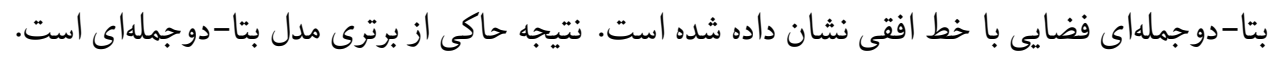

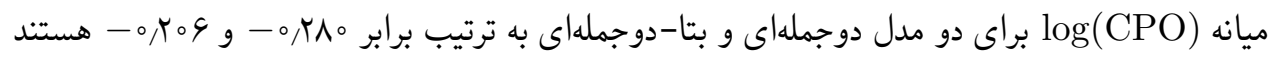
كه به اندازه كافى از هم دور هستند.

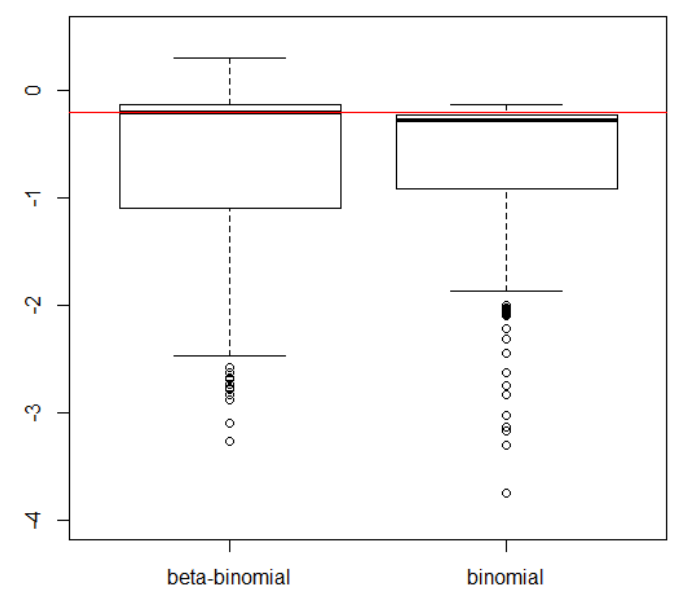

شكل f. نمودار جعبباى مقادير (oP) 1 براى دو مدل دوجملهاى و بتا-دوجملهاى.

در نهايت، مدل بتا-دوجملهاى مدل برتر منتخب است كه نتايج برازش و استنباط بر اساس آن استخراج

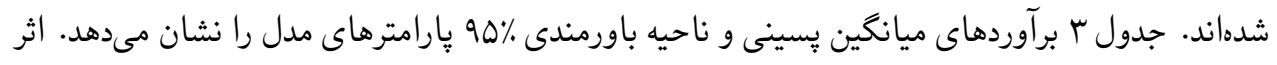

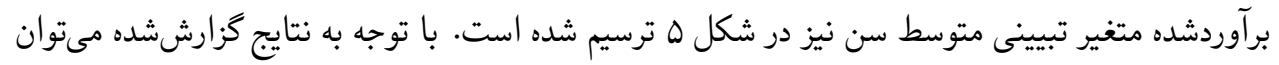
يافتهاى زير را بيان كرد:

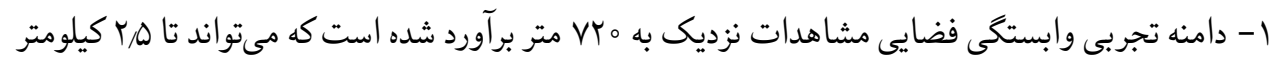

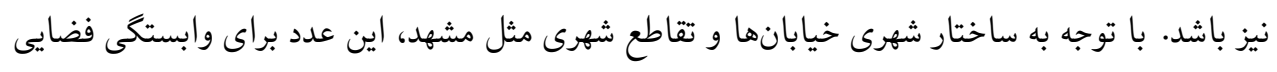

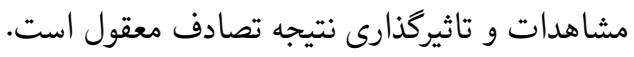

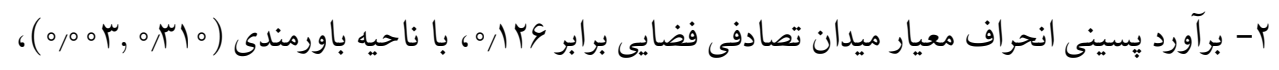

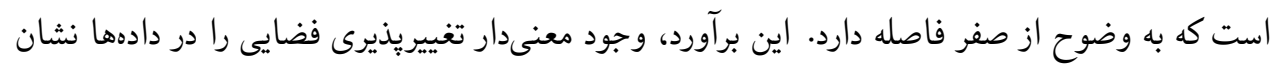




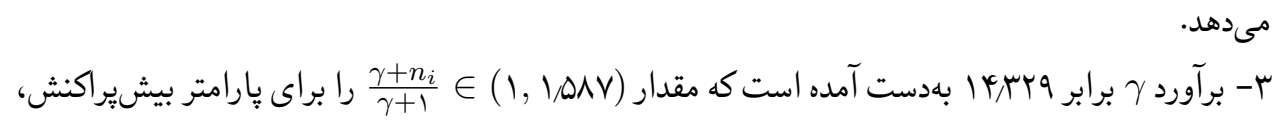

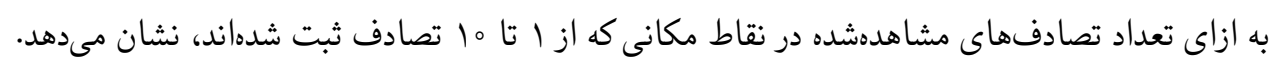

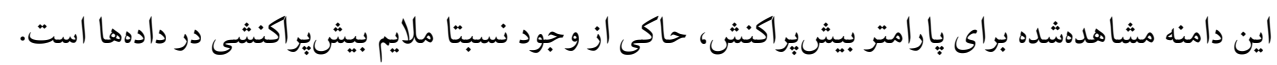

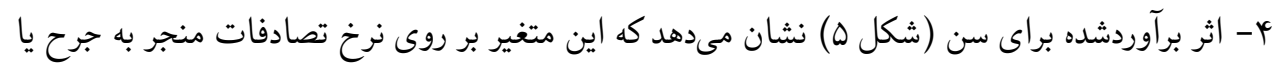

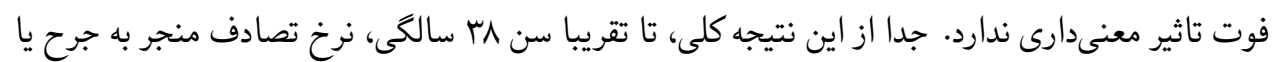

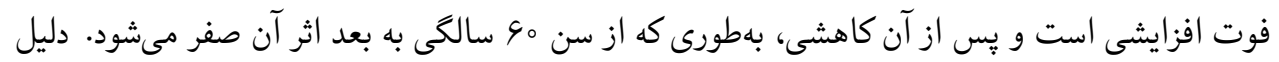

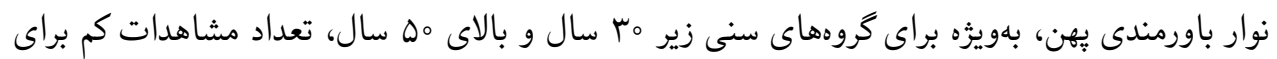

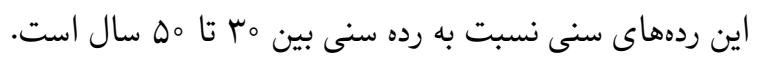

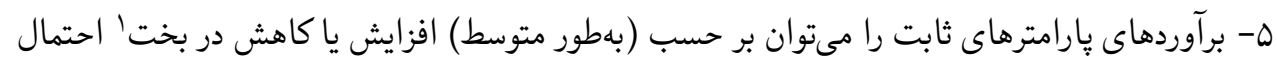

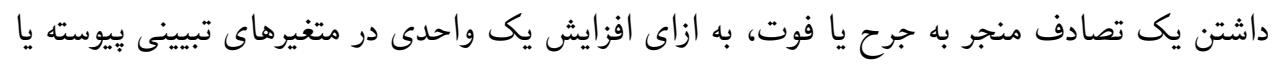

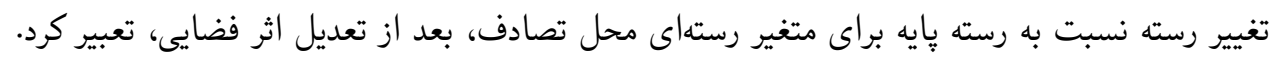

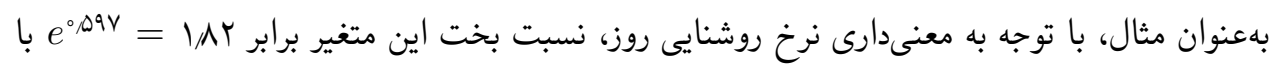

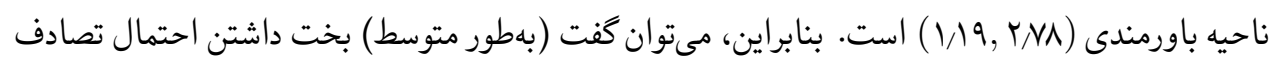

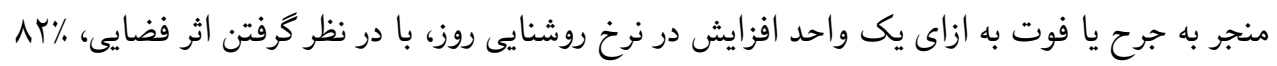

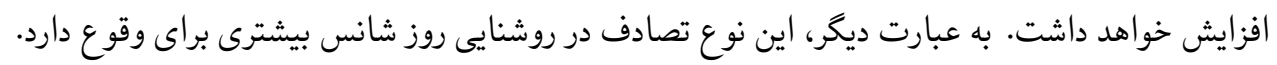

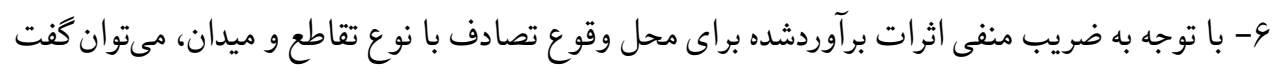

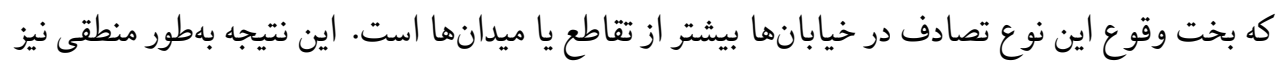

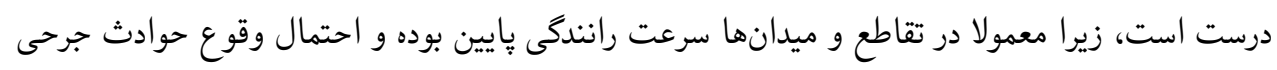

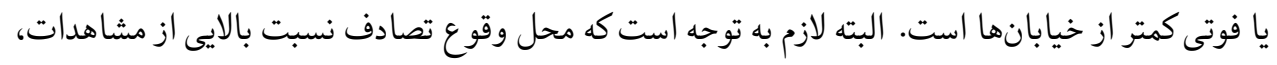

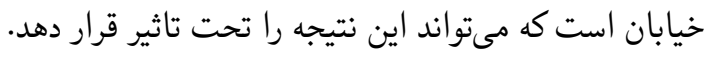

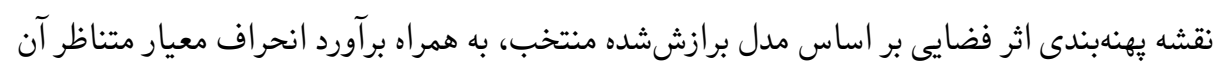

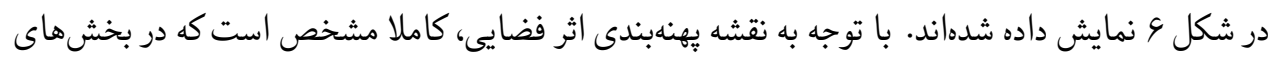

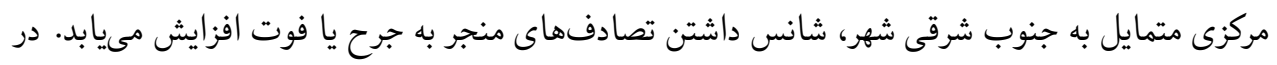

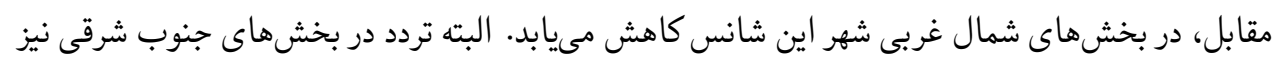

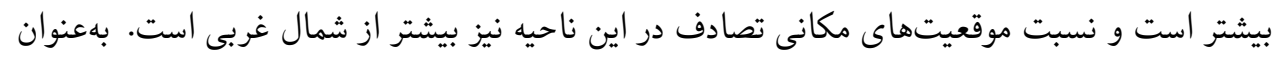


A

\begin{tabular}{|c|c|c|}
\hline ناحيه باورمندى \%\$ & ميانگين & 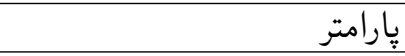 \\
\hline$(-r, Y q r,-1, \Delta Y \Delta)$ & $-1,9 \circ 1$ & ضريب ثابت \\
\hline & & محل تصادف (رده پِايه: خيابان) \\
\hline$(-1,4 \circ r, \circ \Delta \Delta \Delta)$ & $-0, \mu 9 V$ & تقاطع \\
\hline$(-9 Y, 0 Y V, 91, \lambda 91)$ & $-0,09 \pi$ & ميدان \\
\hline$(-0,1 \circ \vee, \circ / \pi \mathrm{I})$ & $0, \mu l k$ & نرخ تعطيلات آخر هفته \\
\hline$(0, l \vee \Delta, 1,0 r r)$ & $0 / 09 V$ & نرخ روشنايى \\
\hline$\left(r, \wedge \circ \Delta, \pi r, r \varphi_{0}\right)$ & $14, \pi r q$ & $\gamma$ \\
\hline$(0,0 \circ Y, Y / \Delta Y Y)$ & oNIV & $r$ \\
\hline$(0,0 \circ \mu, \circ, \mu, \circ)$ & $0,1 Y G$ & $\sigma$ \\
\hline
\end{tabular}

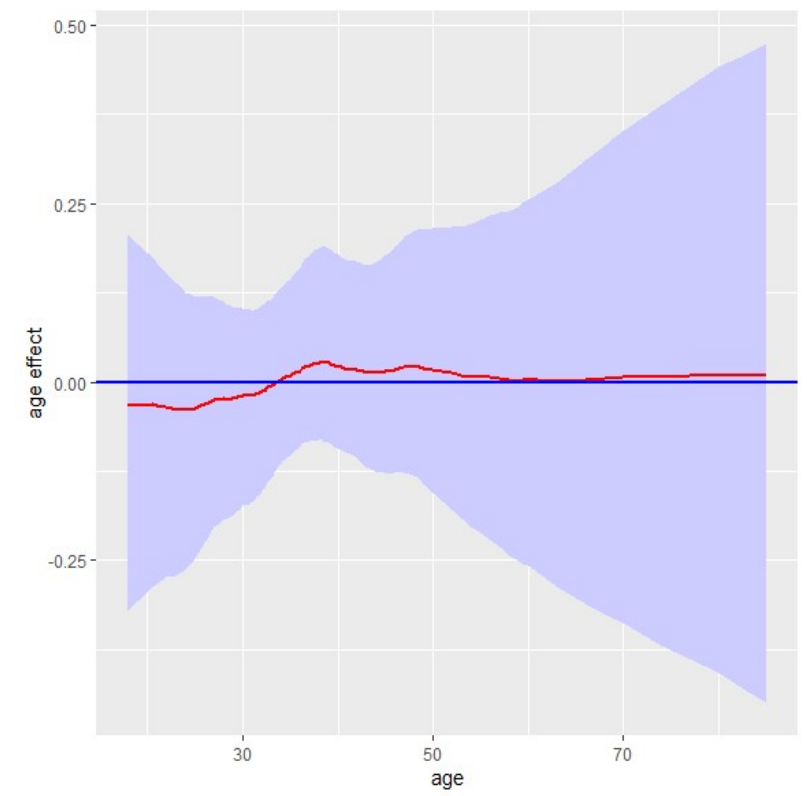

شكل ه. اثر برآوردشده متغير تبيينى متوسط سن راندكان به همراه نوار باورمندى \%\$

نتيجهيرى، نقاط بِرخطر براى وقوع تصادفهاى خطرناك بر روى نقشه مشخص هستند كه مىتواند مورد

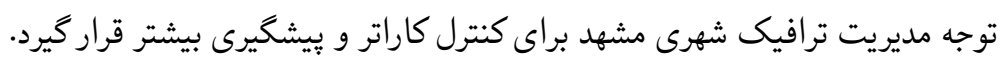



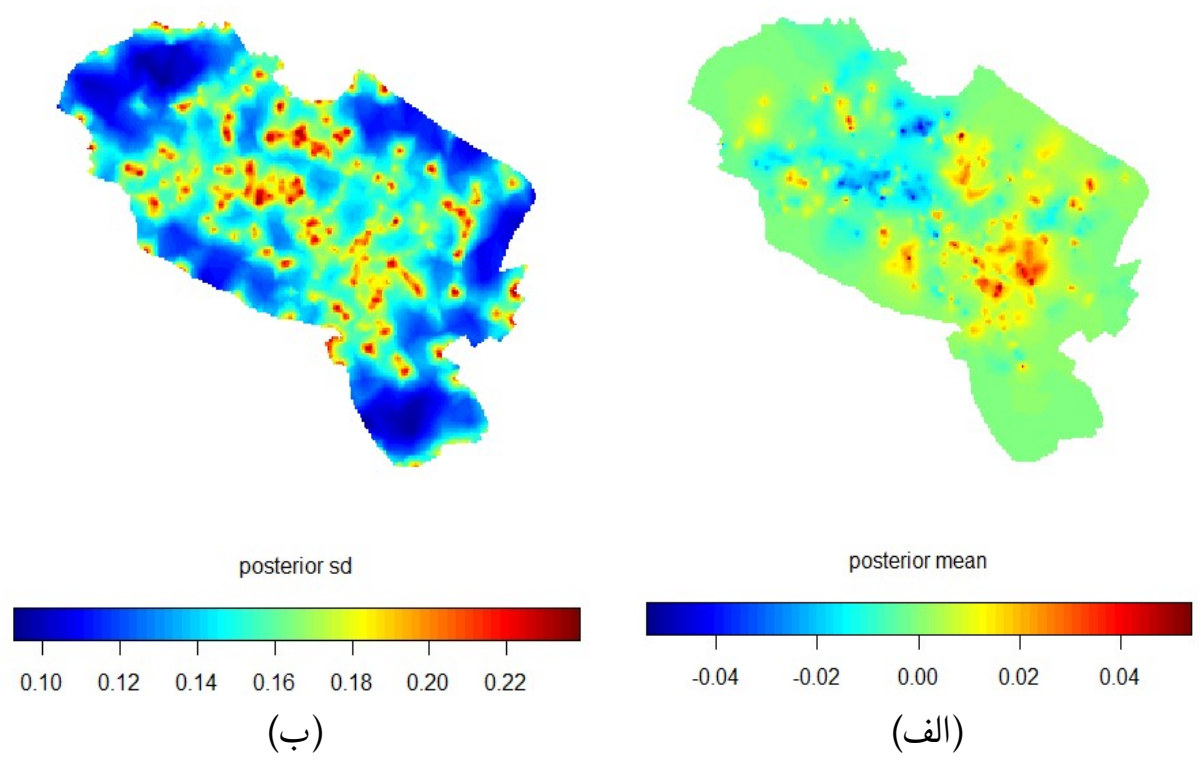

شكل 9. نقشه يهنهبندى برآورد اثر فضايى (الف) و انحراف معيار آن (ب) براى دادههاى تصادفات

\section{بحث و نتيجهگيرى}

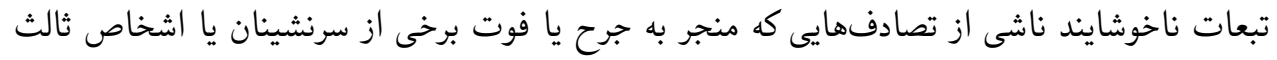

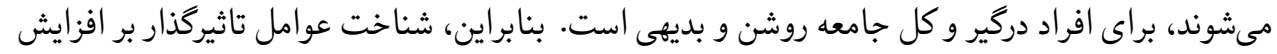

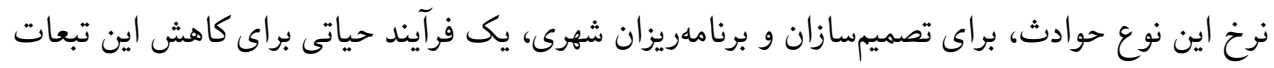

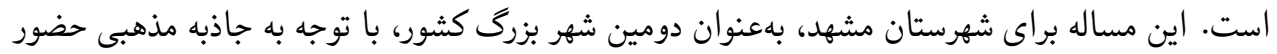

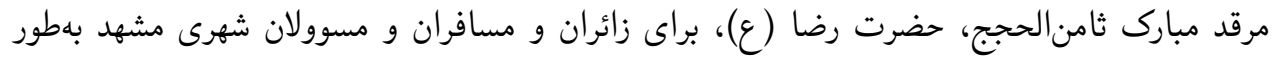

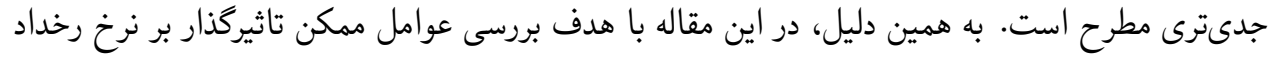

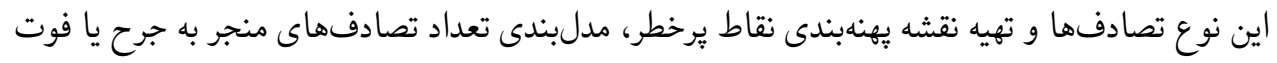
در سرتاسر شهر مشهد مد نظر قرار كرفت.

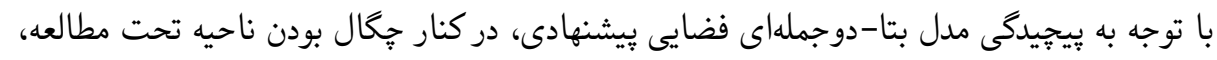

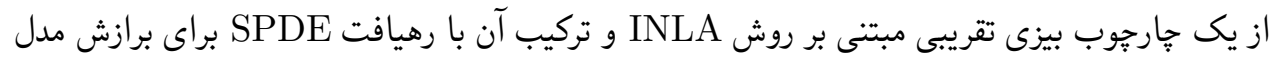

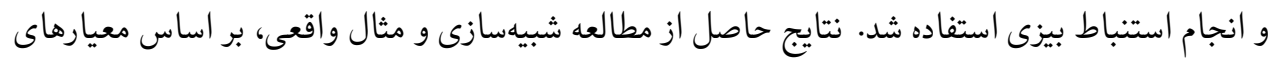

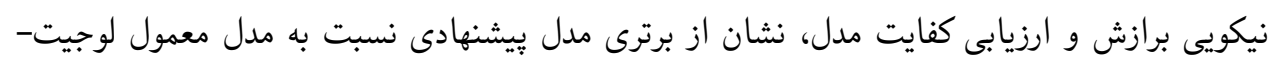


。

دوجملهاى دارد. نقشه يهنهبندى نتيجهشده براى دادههاى تصادف نيز نقاط يرخطر را براى تصميمسازان شهر مشهد نمايش مىدهد. در عمل، در اغلب كاربردهاى واقعى، بيشيراكنشى واقعيتى است كه ديده مى دودود.

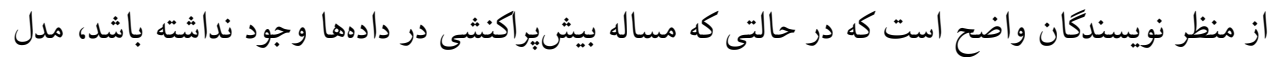

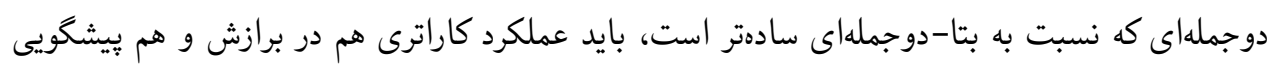

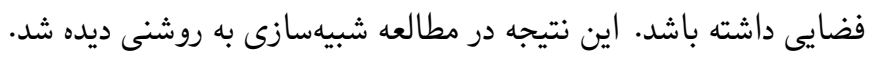

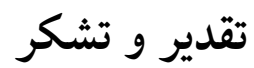

از همكارى معاونت حمل و نقل و ترافيك شهر مشهد براى در اختيار قرار دادن دادههاى تصادفات رانندكى

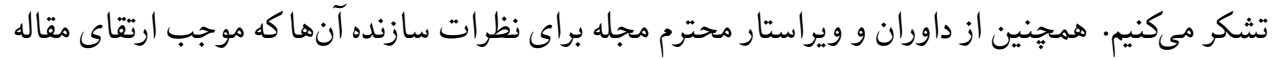

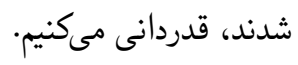

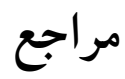

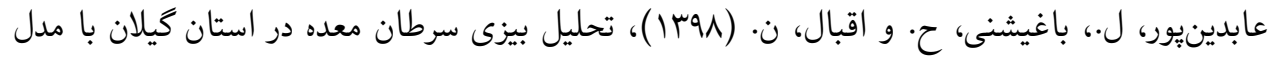

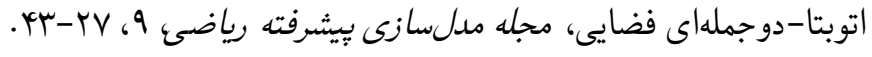

قلىزاده گزور، ك.، محمدزاده، م و قيومى، ز. (Y (IT))، تحليل فضايى رگرسيون جمعى ساختارى و مدلبندى

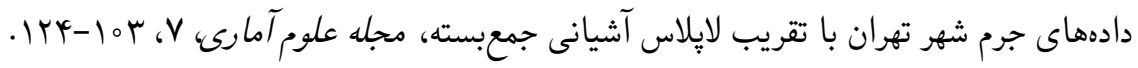

Bandyopadhyay, D., Reich, B. J. and Slate, E. H. (2011), A Spatial BetaBinomial Model for Clustered Count Data on Dental Caries, Statistical Methods in Medical Research, 20, 85-102.

Besag, J., York, J. and Mollie, A. (1991), Bayesian Image Restoration with Two Applications in Spatial Statistics (With Discussion), Annals of the Institute of Statistical Mathematics, 43, 1-59.

Bielby, J., Donnelly, C. A., Pope, L. C., Burke, T. and Woodroffe, R. (2014), Badger Responses to Small-Scale Culling May Compromise Targeted Con- 
trol of Bovine Tuberculosis, Proceedings of the National Academy of Sciences of the United States of America, 111, 9193-9198.

Christensen, O. F., Roberts, G. O. and Skold, M. (2006), Robust Markov Chain Monte Carlo Methods for Spatial Generalized Linear Mixed Models, Journal of Computational and Graphical Statistics, 15, 1-17.

Diggle, P. J. and Ribeiro, P. J. (2006), Model-based Geostatistics, Springer, New York.

Fahrmeir, L., Kneib, T., Lang, S. and Marx, B. (2013), Regression Models, Methods and Applications, Springer, Berlin.

Ferrari, S. and Cribari-Neto, F. (2004), Beta Regression for Modelling Rates and Proportions, Journal of Applied Statistics, 31, 799-815.

Fuglstad, G., Simpson, D. P., Lingren, F. and Rue, H. (2019), Constructing Priors that Penalize the Complexity of Gaussian Random Fields, Journal of the American Statistical Association, 114, 445-452.

Gelman, A., Hwang, J. and Vehtari, A. (2014), Understanding Predictive Information Criteria for Bayesian Models, Statistics and Computing, 24, 997-1016.

Hinde, J. and Demetrio, C. (1998), Overdispersion: Models, and Estimation, Computational Statistics and Data Analysis, 27, 151-170.

Hughes, G. and Madden, L. V. (1993), Using the Beta-Binomial Distribution to Describe Aggegated Patterns of Disease Incidence, Phytopathology, 83, 759-763. 
Kolovos, A., Smith, L. M., Schwab-McCoy, A., Gengler, S. and Yu, H. L. (2016), Emerging Patterns in Multi-Sourced Data Modeling Uncertainty, Spatial Statistics, 18, 300-317.

Krainski, E. T., Gomez-Rubio, V., Bakka, H., Lenzi, A., Castro-Camilo, D., Simpson, D. P., Lindgren, F. and Rue, H. (2018), Advanced Spatial Modeling with Stochastic Partial Differential Equations Using $R$ and INLA, Chapman and Hall/CRC, New York.

Lang, S. and Brezger, A. (2004), Bayesian P-Splines, Journal of Computational and Graphical Statistics, 13, 183-212.

Levin, B. and Reeds, J. (1977), Compound Multinomial Likelihood Functions are Unimodal: Proof of a Conjecture of I. J. Good, The Annals of Statistics, 5, 79-87.

Lindgren, F. and Rue, H. (2015), Bayesian Spatial Modelling with R-INLA, Journal of Statistical Software, 63, DOI: 10.18637/jss.v063.i19.

Lindgren, F., Rue, H. and Lindstrom, J. (2011), An Explicit Link Between Gaussian Fields and Gaussian Markov Random Fields: The Stochastic Partial Differential Equation Approach (With Discussion), Journal of the Royal Statistical Society, Series B, 73, 423-498.

Martins, T. G. and Rue, H. (2014), Extending Integrated Nested Laplace Approximation to a Class of Near-Gaussian Latent Models, Scandinavian Journal of Statistics, 41, 893-912.

McCullach, P. and Nelder, J. A. (1989), Generalized Linear Models, 2nd edn, Chapman, London. 
Najera-Zuloaga, J., Lee, D. J. and Arostegui, I. (2019), A Beta-Binomial Mixed-Effects Model Approach for Analysing Longitudinal Discrete and Bounded Outcomes, Biometrical Journal, 61, 600-615.

Pettit, L. I. (1990), The Conditional Predictive Ordinate for the Normal Distribution, Journal of the Royal Statistical Society, Series B, 52, 175184.

Richards, S. A. (2008), Dealing with Overdispersed Count Data in Applied Ecology, Journal of Applied Ecology, 45, 218-227.

Rue, H. and Held, L. (2005), Gaussian Markov Random Fields: Theory and Applications, Chapman and Hall-CRC Press, London.

Rue, H., Martino, S. and Chopin, N. (2009). Approximate Bayesian Inference for Latent Gaussian Models by Using Integrated Nested Laplace Approximations (With Discussion), Journal of the Royal Statistical Society, Series B, 71, 319-392.

Schwab, A. D. and Marx, D. B. (2015), Beta-Binomial Kriging: An Improved Models for Spatial Rates, Procedia Environmental Sciences, 27, 30-37.

Simpson, D. P., Rue, H., Riebler, A., Martins, T. G. and Sorbye, S. H. (2017), Penalising Model Component Complexity: A Principled, Practical Approach to Constructing Priors, Statistical Science, 32, 1-28.

Skellam, J. G. (1948), A Probability Distribution Derived from the Binomial Distribution by Regarding the Probability of Success As a Variable Between the Sets of Trials, Journal of the Royal Statistical Society, Series B, 10, 257-261. 
Spiegelhalter, D., Best, N., Carlin, B. and Van Der Linde, A. (2002), Bayesian Measures of Model Complexity and Fit, Journal of the Royal Statistical Society, Series B, 64, 583-639.

Stanton, M. C. and Diggle, P. J. (2013), Geostatistical Analysis of Binomial Data: Generalised Linear or Transformed Gaussian Modelling?, Environmetrics, 24, 158-171.

Stein, M. (2005), Space-Time Covariance Functions, Journal of American Statistical Association, 100, 310-321.

Watanabe, S. (2010), Asymptotic Equivalence of Bayes Cross Validation and Widely Applicable Information Criterion in Singular Learning Theory, Journal of Machine Learning Research, 11, 3571-3594.

Whittle, P. (1963), Stochastic Processes in Several Dimensions, Bulletin of the International Statistical Institute, 40, 974-994.

Williams, D. A. (1982), Extra-Binomial Variation in Logistic Linear Models, Applied Statistics, 31, 144-148.

Williams, D. A. (1975), The Analysis of Binary Responses from Toxicological Experiments Involving Reproduction and Teratogenicity, Biometrics, 31, 949-952. 
Journal of Statistical Sciences, Autumn and Winter, 2020

Vol. 14, No. 2, pp 307-334

DOI: $10.29252 /$ jss.13.2.307

\title{
Bayesian Analysis of Spatial Count Data in Finite Popula- tions Using Stochastic Partial Differential Equations
}

Eghbal, N., Baghishani, H.

Department of Statistics, Faculty of Mathematical Sciences, Shahrood University of Technology, Shahrood, Iran

\begin{abstract}
Geostatistical spatial count data in finite populations can be seen in many applications, such as urban management and medicine. The traditional model for analyzing these data is the spatial logit-binomial model. In the most applied situations, these data have overdispersion alongside the spatial variability. The binomial model is not the appropriate candidate to account for the overdispersion. The proper alternative is a beta-binomial model that has sufficient flexibility to account for the extra variability due to the possible overdispersion of counts. In this paper, we describe a Bayesian spatial beta-binomial for geostatistical count data by using a combination of the integrated nested Laplace approximation and the stochastic partial differential equations methods. We apply the methodology for analyzing the number of people injured/killed in car crashes in Mashhad, Iran. We further evaluate the performance of the model using a simulation study.
\end{abstract}

Keywords: Spatial beta-binomial, Overdispersion, Approximate Bayesian approach, Stochastic partial differential equations, Car crashes.

Mathematics Subject Classification (2010): 62H11, 62M30, 91B72. 